\title{
Projected decreases in future marine export production: the role of the carbon flux through the upper ocean ecosystem
}

\author{
Charlotte Laufkötter ${ }^{1,6}$, Meike Vogt ${ }^{1}$, Nicolas Gruber ${ }^{1}$, Olivier Aumont ${ }^{7}$, Laurent Bopp ${ }^{2}$, Scott C. Doney ${ }^{3}$, \\ John P. Dunne ${ }^{5}$, Judith Hauck ${ }^{4}$, Jasmin G. John ${ }^{5}$, Ivan D. Lima ${ }^{3}$, Roland Seferian ${ }^{8}$, and Christoph Völker ${ }^{4}$ \\ ${ }^{1}$ Environmental Physics, Institute of Biogeochemistry and Pollutant Dynamics, ETH Zürich, Zürich, Switzerland \\ ${ }^{2}$ Laboratoire des sciences du climat et de l'environnement (LSCE), IPSL, CEA-UVSQ-CNRS, UMR8212, \\ Gif-sur-Yvette, France \\ ${ }^{3}$ Department of Marine Chemistry \& Geochemistry, Woods Hole Oceanographic Institution, Woods Hole, MA, USA \\ ${ }^{4}$ Alfred Wegener Institute, Helmholtz Centre for Polar and Marine Research, Bremerhaven, Germany \\ ${ }^{5}$ National Oceanic and Atmospheric Administration/Geophysical Fluid Dynamics Laboratory, Princeton, NJ, USA \\ ${ }^{6}$ NOAA/Geophysical Fluid Dynamics Laboratory, Princeton University, Princeton, NJ, USA \\ ${ }^{7}$ Laboratoire de Physique des Oceans, Centre IRD de Bretagne, Plouzane, France \\ ${ }^{8}$ CNRM, Centre National de Recherches Météorologiques, Météo-France/CNRS, 42 Avenue Gaspard Coriolis, \\ 31057 Toulouse, France
}

Correspondence to: Charlotte Laufkötter (c.laufkoetter@gmail.com)

Received: 28 October 2015 - Published in Biogeosciences Discuss.: 14 December 2015

Revised: 23 May 2016 - Accepted: 3 June 2016 - Published: 14 July 2016

\begin{abstract}
Accurate projections of marine particle export production (EP) are crucial for predicting the response of the marine carbon cycle to climate change, yet models show a wide range in both global EP and their responses to climate change. This is, in part, due to EP being the net result of a series of processes, starting with net primary production (NPP) in the sunlit upper ocean, followed by the formation of particulate organic matter and the subsequent sinking and remineralisation of these particles, with each of these processes responding differently to changes in environmental conditions. Here, we compare future projections in EP over the 21 st century, generated by four marine ecosystem models under the high emission scenario Representative Concentration Pathways (RCP) 8.5 of the Intergovernmental Panel on Climate Change (IPCC), and determine the processes driving these changes. The models simulate small to modest decreases in global EP between -1 and $-12 \%$. Models differ greatly with regard to the drivers causing these changes. Among them, the formation of particles is the most uncertain process with models not agreeing on either magnitude or the direction of change. The removal of the sinking particles by remineralisation is simulated to increase in the low and intermediate latitudes in three models, driven by either warming-
\end{abstract}

induced increases in remineralisation or slower particle sinking, and show insignificant changes in the remaining model. Changes in ecosystem structure, particularly the relative role of diatoms matters as well, as diatoms produce larger and denser particles that sink faster and are partly protected from remineralisation. Also this controlling factor is afflicted with high uncertainties, particularly since the models differ already substantially with regard to both the initial (presentday) distribution of diatoms (between 11-94\% in the Southern Ocean) and the diatom contribution to particle formation (0.6-3.8 times higher than their contribution to biomass). As a consequence, changes in diatom concentration are a strong driver for EP changes in some models but of low significance in others. Observational and experimental constraints on ecosystem structure and how the fixed carbon is routed through the ecosystem to produce export production are urgently needed in order to improve current generation ecosystem models and their ability to project future changes. 


\section{Introduction}

Oceanic export production (EP) controls the input of particulate organic matter into the mesopelagic zone and reduces surface ocean $\mathrm{CO}_{2}$ content, thereby directly influencing oceanic carbon uptake (Falkowski et al., 2003; Sarmiento and Gruber, 2006). Accurate projections of global warmingdriven changes in EP are therefore crucial for predicting the oceanic feedback to climate change. The majority of modelling studies that analysed future changes in EP suggested decreases in global integrated future EP (Bopp et al., 2001, 2005; Schmittner et al., 2008; Steinacher et al., 2010; Marinov et al., 2013; Taucher and Oschlies, 2011); however, the magnitude of the global changes is uncertain. Among CMIP5 models, EP changes range from -5 to $-20 \%$ under RCP8.5 (Bopp et al., 2013; Cabré et al., 2014; Fu et al., 2015). Understanding the underlying drivers of EP changes is indispensable to reduce the uncertainty in current projections. Much work has been done on analysing drivers of net primary production (NPP) as one of the main drivers for export in models (Steinacher et al., 2010; Dutkiewicz et al., 2013; Laufkötter et al., 2015). Stratification-induced decreases in nutrient supply in the low latitudes have been suggested as the main driver of NPP changes (Bopp et al., 2005; Steinacher et al., 2010; Marinov et al., 2013). Additionally, Laufkötter et al. (2015) showed warming-induced increases in grazing pressure and other loss processes as an important additional factor responsible for reduced future biomass and NPP. In the Southern Ocean, models project an increase in NPP and EP, but there is little agreement on the mechanisms among the models (Laufkötter et al., 2015; Hauck et al., 2015; Leung et al., 2015).

Beyond the modification by changing NPP, future projections of EP are also affected by changes in the $e$ ratio (also called export efficiency), the fraction of NPP that is exported through the $100 \mathrm{~m}$ depth level. The $e$ ratio represents the net effect of a variety of poorly understood processes that govern the formation of sinking particles in the upper ocean and the decomposition and re-packaging of sinking particles through the water column. Active scientific debate surrounds the contribution of different zoo- and phytoplankton functional types to particle formation (Smetacek et al., 2012; Lomas and Moran, 2011), the importance of a ballasting effect of minerals by protection against degradation or by an increase in the density and hence faster sinking speed (Armstrong et al., 2002; Klaas and Archer, 2002; Wilson et al., 2012; Iversen and Robert, 2015) and temperature effects on particle formation and remineralisation (Kim et al., 2011; Marsay et al., 2015). Marine ecosystem models reflect this ongoing research by incorporating different processes in their equations; e.g. some models include mineral ballasting effects (Moore et al., 2002; Dunne et al., 2012), other models parameterise different particle size classes with different sinking speeds or particle aggregation effects (Aumont and Bopp, 2006). While several publications have anal- ysed trends in NPP, the processes affecting particle formation and sinking have received considerably less attention. In previous studies, decreases in diatom biomass have been shown to be the main driver for global $e$ ratio changes in the models PISCES and BEC (Bopp et al., 2005; Marinov et al., 2010, 2013; Lima et al., 2014).

In this work we identify and compare the drivers responsible for the future global export and $e$ ratio changes projected by four marine ecosystem models run under the Intergovernmental Panel on Climate Change (IPCC) Representative Concentration Pathways (RCP) scenario 8.5 (van Vuuren et al., 2011). We show that changes in NPP and changes in $e$ ratio are of equal importance for the projected changes in export production. We then analyse the carbon fluxes through the modelled ecosystems and the processes and environmental forcing variables causing the changes in $e$ ratio. Our results show that models differ strongly in the dominant carbon pathways through the ecosystem and the sinking behaviour of particles. Consequentially, we find no agreement on the processes leading to the changes in $e$ ratio. In particular, the effects of changes in relative diatom contribution to total biomass exhibit strongly opposing effects both regionally and between models.

\section{Model descriptions}

We analyse projections from four marine ecosystem models coupled to or forced with different Earth system models for the 2012-2100 period under IPCC's emission scenario RCP8.5. We included all model projections in our study where the carbon fluxes between the plankton types and the sinking particle pool are available or recalculable. We refer to the projections using the ecosystem model name. Two of the simulations (models BEC Moore et al., 2002 and REcoM2 Hauck et al., 2013) were obtained from the "MARine Ecosystem Model Intercomparison Project" (MAREMIP; http://pft.ees.hokudai.ac.jp/maremip/index.shtml; Vogt et al., 2013; Sailley et al., 2013; Hashioka et al., 2013). The other two simulations (PISCES Aumont and Bopp, 2006 and TOPAZ Dunne et al., 2013) are ensemble members of the Coupled Model Intercomparison Project 5 (CMIP5; Taylor et al., 2012) runs of these models. The main references describing the models and further information on model set-up, resolution and spin-up time are given in Table 1. An overview on the ecosystem models is given in Table 2 . The ecosystem models differ in the number of plankton functional types (PFTs) they consider, in the dependence of phytoplankton growth on light, nutrients and temperature, in cell stochiometry, in carbon routing through the ecosystem and in sinking behaviour of the particles. In terms of PFT structure, all models parameterise at least two phytoplankton PFTs, diatoms and nano-phytoplankton, and one zooplankton type. TOPAZ and BEC additionally model a diazotrophic phytoplankton, PISCES differentiates between meso- and microzooplank- 


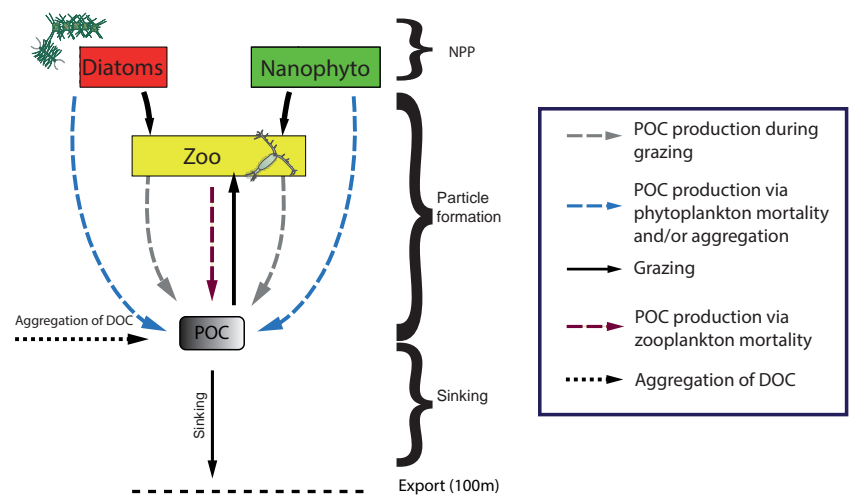

Figure 1. Illustration of the different pathways along which carbon is routed to the sinking particle pool. The boxes depict the biomass components (diatoms, nano-phytoplankton, zooplankton and POC in most models). The arrows indicate carbon fluxes between the different compartments, caused by grazing, aggregation or mortality.

ton. REcoM2 parameterises nutrient limitation by three different nutrients (nitrate, iron and silicate). The other models additionally include phosphate and ammonium. In this work we focus on the carbon fluxes within the ecosystem and on export production, which will be described in the following. The full equations and parameters for particulate organic carbon formation and sinking in the individual models are given in the Appendix. For the equations governing phytoplankton growth and NPP in all models, we refer to Laufkötter et al. (2015).

\subsection{Carbon fluxes in the ecosystem models}

In the following we describe the processes related to formation and sinking of non-living particulate organic carbon in the models as illustrated in Fig. 1. We do not consider here the generation, decomposition and export of dissolved organic carbon (DOC), even though DOC contributes about $20 \%$ to global export (Najjar et al., 2007; Hansell and Carlson, 2002). This choice is motivated by particle export being much better constrained by observations and also because the DOC export fluxes are seldom available from models (unless specifically saved) owing to the need to compute them from a full physical flux analysis.

Organic carbon is created during NPP of the phytoplankton functional types (p-PFTs) within the euphotic zone. We only consider NPP in the upper $100 \mathrm{~m}$. NPP $i$ of a p-PFT $i$ is calculated in all models as the product of carbon biomass $P_{i}$ and its growth rate $\mu_{i}$. The growth rate is modified by light and nutrient limitation and temperature. Total NPP is the sum of $\mathrm{NPP}_{i}$ of the respective p-PFTs:

$\mathrm{NPP}=\sum_{i} \mu_{i} \times P_{i}$.

Organic carbon is then routed through the simulated ecosystem components, partly forming new biomass, partly being converted back to inorganic carbon or dissolved organic carbon and partly forming non-living particulate organic carbon (POC), in the following called sinking particles or just particles.

The mechanisms by which sinking particles are formed are faecal pellet production during grazing on the phytoplankton types $\left(G_{\mathrm{POC}}^{\mathrm{ZoO}_{i} \rightarrow \text { phyto }_{j}}\right)$ and first-order biomass losses via aggregation or mortality of the different phytoplankton and zooplankton types ( $A_{\mathrm{POC}}^{i}$, not parameterised in all models). In PISCES, particles also originate from the aggregation of DOC. Moreover, PISCES also parameterises zooplankton grazing on particles. An overview of which mechanism is included in which model is shown in Table 3. In all models, the total particle formation is then modelled as the sum of the organic carbon arriving into sinking particles via the different pathways:

particle formation $=\sum_{i, j} G_{\mathrm{POC}^{2} \rightarrow \mathrm{phyto}_{i}}^{\mathrm{zoo}}+\sum_{i} A_{\mathrm{POC}}^{i}$.

Once formed, particles start sinking towards the ocean interior. During sinking, particles are subject to degradation and remineralisation; i.e. they are transformed back into their inorganic constituents by zooplankton and bacteria. As a result, particle concentration decreases with depth. The amount of particles that survive degradation in the upper ocean depends on the strength of remineralisation/degradation and the particle sinking speed.

In the parameterisations of the models, particle degradation depends linearly on particle concentration and is temperature dependent in REcoM2 and PISCES but independent of temperature in TOPAZ. REcoM2 considers one class of particles, which sink with a sinking speed that increases with depth (Hauck et al., 2013; Kriest and Oschlies, 2008). PISCES differentiates between two types of particles, small and large, that sink with different sinking speeds (Aumont and Bopp, 2006). BEC and TOPAZ parameterise a ballasting effect on the particles, where a fraction of the carbon that is associated with mineral ballast is protected from remineralisation (Moore et al., 2013; Dunne et al., 2013). Moreover, in BEC a fraction of the organic carbon is associated with a ballasting material (silicate, $\mathrm{CaCO}_{3}$ or lithogenic dust) and therefore has a longer remineralisation length scale (Moore et al., 2004, 2013).

We define particle EP as the amount of particles that sink through the $100 \mathrm{~m}$ depth level. While this depth does not necessarily reflect the amount of carbon that reaches the deep ocean, it separates surface processes from mechanisms governing deep ocean carbon fluxes and is useful for comparing the models with each other and with observations. The fraction of NPP that contributes to EP is often called $e$ ratio (or export efficiency):

$e$ ratio $=\frac{\mathrm{EP}}{\mathrm{NPP}}$. 
Table 1. A short description of the simulations used in this work, including spin-up times, the main references for both the ecosystem models and the Earth system model they are coupled to or forced with.

\begin{tabular}{|c|c|c|c|c|c|c|c|}
\hline Earth system model & Reference & Ocean model & Ecosystem model & Reference & $\begin{array}{l}\text { Spin-up } \\
\text { (years, offline }+ \text { online })\end{array}$ & Project & Coupling \\
\hline CESM1 & $\begin{array}{l}\text { Hurrell et al. (2013), } \\
\text { Lindsay et al. (2014) }\end{array}$ & POP & $\mathrm{BEC}$ & Moore et al. (2013) & $1025+150$ & MAREMIP & fully coupled \\
\hline GFDL-ESM2M & Dunne et al. $(2012,2013)$ & MOM & TOPAZ & Dunne et al. (2013) & $1+1000$ & CMIP5 & fully coupled \\
\hline CNRM-CM5 & Voldoire et al. (2012) & NEMO & PISCES & Aumont and Bopp (2006) & $3000+300$ & CMIP5 & fully coupled \\
\hline MIROC5 & $\begin{array}{l}\text { Watanabe et al. (2011), } \\
\text { Kawamiya et al. (2000) }\end{array}$ & MITgcm & REcoM2 & Hauck et al. (2013) & $0+112$ & MAREMIP & ocean only \\
\hline
\end{tabular}

Table 2. Overview about the four ecosystem models used in this work, including the number of phyto- and zooplankton types, the nutrients that can limit phytoplankton growth and a description of the stoichiometry. In terms of nutrients, $\mathrm{NO}_{3}$ is nitrate, $\mathrm{SiO}_{4}$ silicate, $\mathrm{Fe}$ iron, $\mathrm{NH}_{4}$ ammonium and $\mathrm{PO}_{4}$ phosphate. In terms of stoichiometry, " $R$ " depicts Redfield Ratio, whereas " $V$ " depicts variable stoichiometry.

\begin{tabular}{|c|c|c|c|c|}
\hline Ecosystem model & Nutrients & Phytoplankton types & Zooplankton types & Stochiometry \\
\hline REcoM2 & $3\left(\mathrm{NO}_{3}, \mathrm{SiO}_{4}, \mathrm{Fe}\right)$ & $\begin{array}{l}2 \text { (diatom, nano-, im- } \\
\text { plicit calcification) }\end{array}$ & 1 & $V(\mathrm{C}, \mathrm{N}, \mathrm{Si}, \mathrm{Chl}),(\mathrm{C}: \mathrm{Fe})$ fix \\
\hline $\mathrm{BEC}$ & $5\left(\mathrm{NO}_{3}, \mathrm{NH}_{4}, \mathrm{PO}_{4}, \mathrm{SiO}_{4}, \mathrm{Fe}\right)$ & $\begin{array}{l}3 \text { (diatom, nano-, dia- } \\
\text { zotroph, implicit calci- } \\
\text { fication) }\end{array}$ & 1 & $R(\mathrm{C}: \mathrm{N}: \mathrm{P}), V(\mathrm{Si}, \mathrm{Chl}, \mathrm{Fe})$ \\
\hline TOPAZ & $5\left(\mathrm{NO}_{3}, \mathrm{NH}_{4}, \mathrm{PO}_{4}, \mathrm{SiO}_{4}, \mathrm{Fe}\right)$ & $\begin{array}{l}3 \text { (large separated into } \\
\text { diatoms and other eu- } \\
\text { karyotes, nano-, dia- } \\
\text { zotrophs, implicit calci- } \\
\text { fication) }\end{array}$ & 1 (with implicit grazing) & $R(\mathrm{C}: \mathrm{N}), V(\mathrm{P}, \mathrm{Si}, \mathrm{Chl}, \mathrm{Fe})$ \\
\hline PISCES & $5\left(\mathrm{NO}_{3}, \mathrm{NH}_{4}, \mathrm{PO}_{4}, \mathrm{SiO}_{4}, \mathrm{Fe}\right)$ & $\begin{array}{l}2 \text { (diatom, nano-, im- } \\
\text { plicit calcification) }\end{array}$ & 2 (micro- and mesozooplankton) & $R(\mathrm{C}: \mathrm{N}: \mathrm{P}), V(\mathrm{Si}, \mathrm{Chl}, \mathrm{Fe})$ \\
\hline
\end{tabular}

The $e$ ratio summarises both the formation and the sinking of particles. We therefore decompose it into two ratios, which describe the efficiency with which particles are formed and the efficiency with which particles are sinking, respectively:

$e$ ratio $=p$ ratio $\times s$ ratio,

where the $p$ ratio is the fraction of NPP that is formed to particles:

$p$ ratio $=\frac{\text { particle formation }}{\text { NPP }}$

and the $s$ ratio the fraction of particles that escape remineralisation at surface and sink through the $100 \mathrm{~m}$ depth level:

$s$ ratio $=\frac{\mathrm{EP}}{\text { particle formation }}$.

If the $p$ ratio is high, a large fraction of NPP is turned into POC. If the $s$ ratio is high, a large fraction of the particles sinks through the $100 \mathrm{~m}$ depth level, i.e. only a small part is remineralised. A conceptional illustration of the different ratios is shown in Figs. 1 and $6 a$.

\subsection{Factors influencing the $p$ ratio}

The $p$ ratio (the efficiency of particle formation) can be calculated as the sum of the efficiencies of the particle formation mechanisms:

$p$ ratio $=\frac{\sum_{i, j} G_{\mathrm{POC}}^{\mathrm{zoo}_{i} \rightarrow \mathrm{phyto}_{j}}+\sum_{i} A_{\mathrm{POC}}^{i}}{\mathrm{NPP}}$.

In the following we describe the factors influencing efficiency of particle formation during aggregation and grazing. We use the terms "grazing efficiency" and "aggregation efficiency" to describe the fraction of NPP that is transformed into particles via grazing and aggregation processes, respectively.

\subsubsection{Particle formation via phytoplankton aggregation}

Phytoplankton aggregation describes the collision and coagulation of phytoplankton cells, which results in larger aggregates that sink (Burd and Jackson, 2009). In all models (except for TOPAZ that does not account for aggregation), aggregation losses of phytoplankton depend quadratically on biomass, such that they are small at low biomass levels but become increasingly important under bloom conditions. In BEC and PISCES they are calculated as

$$
\begin{aligned}
& A_{\mathrm{POC}\{\mathrm{PISCES}\}}^{i}=p_{i} \times P_{i}^{2}, \\
& A_{\mathrm{POC}\{\mathrm{BEC}\}}^{i}=\min \left\{\begin{array}{l}
p_{\mathrm{i}} \times P_{\mathrm{i}}^{2} \\
a_{\mathrm{i}}^{\max } \times P_{\mathrm{i}},
\end{array}\right.
\end{aligned}
$$


Table 3. Overview about the processes implemented in the ecosystem models that affect particle formation and particle sinking. "Agg." is short for aggregation. $\mathrm{SiO}_{3}$ and $\mathrm{CaCO}_{3}$ are silicate and calcium carbonate. For the models with constant sinking speed and remineralisation rates, we give the remineralisation length scale of not-ballasted POC. In BEC the particle sinking is calculated implicitly; i.e. all particles sink and remineralise instantly in the grid point where they originate. In REcoM2 and PISCES the particle sinking speed increases with depth, we therefore give the minimum and maximum sinking speed. In TOPAZ and PISCES, the remineralisation rate decreases in oxygen depleted water, we give the value for well-oxygenated conditions.

\begin{tabular}{|c|c|c|c|c|}
\hline Process & REcoM2 & $\mathrm{BEC}$ & TOPAZ & PISCES \\
\hline Phyto. agg & Yes & Yes & No & Yes \\
\hline Agg. of DOC to POC & No & No & No & Yes \\
\hline Grazing of particles & No & No & No & Yes \\
\hline Ballasting & None & $\mathrm{SiO}_{3}, \mathrm{CaCO}_{3}$, dust & $\mathrm{SiO}_{3}$, calcite, aragonite, dust & None \\
\hline Different particle sizes & No & No & No & large and small \\
\hline Remin. rate $\left(d^{-1}\right)$ & $\begin{array}{l}0.06-0.32 \\
\left(\text { at } 0-30^{\circ} \mathrm{C}\right)\end{array}$ & implicit & 0.53 & $\begin{array}{l}0.025-0.24 \\
\left(\text { at } 0-30^{\circ} \mathrm{C}\right)\end{array}$ \\
\hline Sinking Speed $\left(\mathrm{m} \mathrm{d}^{-1}\right)$ & $20-120$ & implicit & 100 & $\begin{array}{l}2 \text { (small POC), } \\
\text { 30-200 (large POC) }\end{array}$ \\
\hline Remin. length scale (m) & $\begin{array}{l}175-590 \\
\left(\text { at } 0-30^{\circ} \mathrm{C}\right)\end{array}$ & 200 & 188 & $\begin{array}{l}8.3-80\left(\text { small POC at } 30-0^{\circ} \mathrm{C}\right) \\
205-2600\left(\text { large } \mathrm{POC} \text { at } 30-0^{\circ} \mathrm{C}\right)\end{array}$ \\
\hline
\end{tabular}

Table 4. Observed and modelled present-day globally integrated NPP, particle export production, grazed fraction of NPP and diatom contribution to total export production. The fraction of NPP that is grazed is from Calbet and Landry (2004) for microzooplankton and has been calculated as mesozooplankton grazing (Calbet, 2001) divided by NPP for mesozooplankton. For the models with one zooplankton type (TOPAZ, BEC, REcoM2) we give the total percentage of NPP that is grazed. For PISCES we differentiate between the part that is grazed by microzooplankton and the part that is grazed by mesozooplankton. The estimate for diatom contribution to total export is from Jin et al. (2006). This variable is only available in REcoM2. For the other models, we show the diatom contribution to particle formation in parentheses*. Due to different sinking behaviour of the particles, the diatom contribution to global EP is presumably higher.

\begin{tabular}{lrrrr}
\hline Model & Global NPP & Global EP & $\begin{array}{r}\text { Grazed \% } \\
\text { of NPP }\end{array}$ & $\begin{array}{r}\text { Diatom contribution } \\
\text { to global EP }\end{array}$ \\
\hline BEC & 53.4 & 7.7 & $77 \%$ & $(38 \%)^{*}$ \\
TOPAZ & 81.3 & 7.6 & $99 \%$ & $(46 \%)^{*}$ \\
PISCES & 24.1 & 4.6 & micro: $57 \%$. meso: $21 \%$ & $(14 \%)^{*}$ \\
REcoM2 & 29.5 & 7.2 & $4.2 \mathrm{e}^{-7} \%$ & $46 \%$ \\
Observations & $50.7 \pm 9.5$ & $(9.6)^{\mathrm{a}}$ & total: $70-86 \%$ & $36-43 \%$ \\
& & $(12.9)^{\mathrm{b}}$ & micro: $59-75 \%$ & \\
& & $4.0^{\mathrm{c}}$ & meso: $11.8 \%$ & \\
\hline
\end{tabular}

The observed values are from Westberry et al. (2008) for NPP. ${ }^{a}$ Schlitzer (2004) and ${ }^{b}$ Laws et al. (2000) for total (POC + DOC) export production. ${ }^{\mathrm{c}}$ Henson et al. (2012) and ${ }^{\mathrm{d}}$ Siegel et al. (2014) for particle export production.

where $p_{i}$ denotes a mortality rate, which is constant and has the same value for diatoms and nano-phytoplankton in both models (see Tables A1 and A4 for parameter values). $P_{i}$ denotes the biomass of PFT $i$. In BEC, at biomass concentrations $>22 \mathrm{mmolC} \mathrm{m}^{-3}$ aggregation grows linearly with biomass. In PISCES the aggregation rate is reduced by $99 \%$ below the mixed layer depth. Moreover, aggregation increases under nutrient limitation for diatoms, resulting in an increasingly higher diatom aggregation than nanophytoplankton aggregation under stronger nutrient limitation (see Table A2 in the Appendix). While in BEC and PISCES the aggregation of PFT $i$ depends on biomass of $i$ as described in Eq. (9), the aggregation of PFT $i$ in REcoM2 depends on the total living and dead particle concentration, i.e. $J$ includes diatoms, nano-phytoplankton and detritus (parameter values listed in Table A3): $A_{\mathrm{POC}\{\mathrm{REcoM} 2\}}^{i}=$ $\sum_{j \in \mathrm{J}}\left(p_{j} \times P_{j}\right) \times P_{i}$

In REcoM2, aggregation depends on total biomass and is independent of the diatom fraction. In contrast, in both BEC and PISCES aggregation depends on the biomass of the individual PFTs. Because of the exponential nature of the aggregation equations, high and low diatom fractions result in higher aggregation than intermediate diatom fractions in BEC and PISCES. 
Aggregation of DOC to small and big particles $\left(\mathrm{POC}_{s}\right.$, $\mathrm{POC}_{b}$ ) is parameterised only in PISCES and is calculated as

$$
\begin{aligned}
\Phi^{\mathrm{DOC} \rightarrow \mathrm{POC}_{s}} & =\phi_{1} \times s_{h} \times \mathrm{DOC}^{2}+\phi_{2} \times s_{h} \\
& \times \mathrm{DOC} \times \mathrm{POC}_{s}+\phi_{3} \times \mathrm{DOC}^{2}, \\
\Phi^{\mathrm{DOC} \rightarrow \mathrm{POC}_{b}} & =\phi_{4} \times s_{h} \times \mathrm{DOC} \times \mathrm{POC}_{b} .
\end{aligned}
$$

Here, $\phi_{i}$ are constant aggregation rates, and $s_{h}$ denotes the shear rate set to $1 \mathrm{~s}^{-1}$ within the mixed layer and $0.01 \mathrm{~s}^{-1}$ elsewhere.

\subsubsection{Particle formation via grazing}

Another important source of particles is faecal pellet production during grazing. Particle formation during grazing is generally calculated as

$G_{\mathrm{POC}}^{\mathrm{zoo}_{i} \rightarrow \text { phyto }_{j}}=f_{\text {graz }}^{\rightarrow \text { POC }} \times u_{\text {max }} \times T_{f} \times\{P$ dependence $\} \times Z_{i}$,

where $f_{\text {graz }}^{\rightarrow}$ denotes the fraction of the grazed material that is routed to POC. $f_{\text {graz }}^{\rightarrow}$ POC is constant in REcom2. In BEC and TOPAZ, a bigger fraction of grazed diatoms is routed to POC than grazed nano-phytoplankton. In PISCES, it does not depend on food source; however, a higher/lower fraction of material is routed to POC when grazed by mesozooplankton/microzooplankton. We call the particle formation via grazing on diatoms and nano-phytoplankton "diatom grazing flux" and "nano-phytoplankton grazing flux", respectively. $u_{\max }$ denotes the maximal grazing rate and is also constant in all models. In BEC and REcoM2, the grazing rate is higher on nano-phytoplankton than on diatoms due to parameter choices (Tables A1 and A3; in PISCES the microzooplankton grazing rate is constant/independent of prey but higher than the mesozooplankton grazing rate). $T_{f}$ describes the temperature sensitivity of zooplankton grazing. All models use the same temperature function for phytoplankton growth and zooplankton grazing, except for mesozooplankton in PISCES, which has a stronger temperature dependence $\left(Q_{10, \text { meso }}=2.14, Q_{10, \text { other }}=1.8\right.$ in PISCES $) . Z_{i}$ denotes zooplankton biomass, and $P_{j}$ dependence describes the dependence on biomass of phytoplankton $j$. Three models use a Holling type III function (sigmoidal shape, both low end threshold and high end saturating $P$ dependence) for $P$ dependence, albeit with different parameterisations. Mesozooplankton grazing in PISCES uses a Holling type II function (saturating dependence without a low threshold). Additionally, PISCES is the only model that parameterises grazing on particles. Mesozooplankton grazes on large particles according to a Michaelis-Menten type function:

$G^{\text {meso } \rightarrow \mathrm{POC}_{\mathrm{b}}}=g_{\mathrm{FF}} \times \omega^{\mathrm{POC}_{\mathrm{b}}} \times T_{f} \times \mathrm{POC}_{\mathrm{b}} \times Z_{\text {meso }}$,

where $g_{\mathrm{FF}}$ denotes the maximum grazing rate on particles and $\omega^{\mathrm{POC}_{\mathrm{b}}}$ is the sinking speed of the big particles. The sinking speed $\omega^{\mathrm{POC}_{\mathrm{b}}}$ increases with depth but does not change over time.
Particle formation in TOPAZ differs in several ways from particle formation in other models. First, TOPAZ does not calculate aggregation or mortality of phytoplankton; grazing is the only phytoplankton loss rate and also the only mechanism with which particles are produced. Second, zooplankton grazing is modelled implicitly and does not depend on zooplankton biomass but only on phytoplankton biomass and temperature. Third, the fraction of grazed material that is routed to POC $\left(f_{\text {graz }}^{\rightarrow \text { POC }}\right)$ is not constant like in the other models but depends on temperature, with higher temperatures leading to lower POC formation in favour of DOC production and remineralisation. In contrast to the other models, grazing on diazotrophs in TOPAZ also leads to particle formation. However, less than $1 \%$ of NPP is transferred along this pathway and hence we will not discuss diazotroph grazing further. Finally, a much higher fraction of grazed diatoms is routed to POC (the partitioning depends on temperature, the biggest difference is at $0{ }^{\circ} \mathrm{C}$ where $93 \%$ of diatoms vs. $18 \%$ of nano-phytoplankton are routed to POC).

\subsubsection{Particle formation via zooplankton mortality}

The last mechanism by which particles are created in models is zooplankton mortality, which represents mortality due to consumption by higher trophic levels that are not explicitly modelled. A fraction of this biomass loss due to mortality is assumed to end up as fecal pellets from larger zooplankton as well as dead zooplankton carcasses that sink. Zooplankton mortality is calculated as a function of zooplankton concentration. The functional form varies among models with some models assuming a quadratic dependency (REcoM2, PISCES) and others assuming both a linear and a quadratic dependency (BEC). In TOPAZ, the carbon due to zooplankton mortality is immediately remineralised and therefore not further discussed here. In REcoM2, zooplankton mortality is calculated as

$Z_{\mathrm{REcoM} 2}^{\mathrm{mort}}=p_{\text {zoo }} \times Z^{2}$,

where $Z$ denotes zooplankton biomass and $p_{\text {zoo }}$ a mortality rate. The biomass loss due to mortality is entirely routed to the sinking particle pool. BEC uses the sum of a linear and a quadratic mortality:

$Z_{\mathrm{BEC}}^{\mathrm{mort}}=m_{\mathrm{zoo}} Z+p_{\mathrm{zoo}} Z^{2}$,

where $m_{\text {zoo }}$ denotes a linear mortality rate and $Z, p_{\text {zoo }}$ as above. Particle formation during zooplankton mortality depends on the food source, with a higher fraction being routed to POC when grazing on diatoms as zooplankton is assumed to represent rather larger mesozooplankton when feeding on diatoms.

In PISCES, microzooplankton mortality is a function of zooplankton biomass; moreover, it depends on temperature $\left(T_{f}\right)$ and on oxygen levels:

$$
Z_{\text {PISCES }}^{\text {micromort }}=m_{\text {micro }} \times T_{f} \times \frac{Z_{\text {micro }}}{K_{\text {micro }}+Z_{\text {micro }}} \times Z_{\text {micro }} \times f\left(\mathrm{O}_{2}\right) .
$$


The oxygen factor $f\left(\mathrm{O}_{2}\right)$ is set to 1.0 for oxygen levels $>6 \mu \mathrm{mol} \mathrm{O}_{2} \mathrm{~L}^{-1}$ and decreases strongly below $6 \mu \mathrm{mol} \mathrm{O} \mathrm{O}_{2} \mathrm{~L}^{-1}$. In contrast to the other models, PISCES separates between meso- and microzooplankton. Mesozooplankton mortality consists of a linear part and a quadratic closure term:

$$
\begin{aligned}
Z_{\mathrm{PISCES}}^{\text {mesomort }} & =m_{\text {meso }} \times T_{f} \times \frac{Z_{\text {meso }}}{K_{\text {meso }}+Z_{\text {meso }}} \times Z_{\text {meso }} \\
& \times f\left(\mathrm{O}_{2}\right)+p_{\text {meso }} \times Z_{\text {meso }}^{2} .
\end{aligned}
$$

A constant fraction (35\%) of the biomass losses due to microzooplankton mortality and the linear part of mesozooplankton mortality are routed to the small particle pool. The mesozooplankton biomass loss due to the quadratic closure term is routed to big particles.

In addition to the mortality losses, microzooplankton suffer grazing losses from mesozooplankton.

\subsection{Data processing}

Our analysis is based on depth-resolved monthly mean output for the 2012-2100 period. To enable comparison between models, we regridded the PISCES output to a $360 \times 180$ degree grid using the bilinear regridding algorithm of the Earth System Modeling Framework (ESMF) as part of the NCAR Command Language (NCL) version 6.1.2. All other models (BEC, TOPAZ and REcoM2) provided output on a $360 \times 180$ degree grid. The carbon fluxes through the ecosystem (grazing, aggregation and mortality fluxes) were not included in the BEC output and have been recalculated using monthly mean data and the equations as given in the Appendix. All changes presented in this work have been calculated by taking the difference between the 2012-2031 and 2081-2100 periods. The diagrams showing the mean carbon fluxes in different regions have been calculated by taking temporal and spatial averages for the first 20 years of model output.

\section{Model evaluation}

The models presented in this study have all been evaluated against observations individually in previous studies (see references in Table 1). In the following, we give a brief overview on model skill in simulating the most important variables for this work. A comparison between observationally based estimates for global NPP and export production is given in Table 4. Modelled NPP ranges between $24.1 \mathrm{GtC} \mathrm{yr}^{-1}$ (PISCES) and $81.3 \mathrm{GtC} \mathrm{yr}^{-1}$ (TOPAZ), the latter exceeding the satellite-based estimates of NPP $\left(50.7 \pm 9.5 \mathrm{GtC} \mathrm{yr}^{-1}\right.$, Carr et al., 2006). A further evaluation of NPP including its spatial structure is given in Laufkötter et al. (2015). The simulated global annual particle export fluxes (EP) range from 4.6 to $7.7 \mathrm{GtC} \mathrm{yr}^{-1}$, which is at the lower end but within the range of the observational estimates (Table 4). A re- (a) BEC

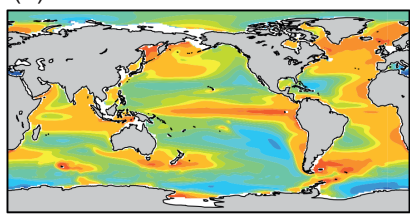

(c) TOPAZ

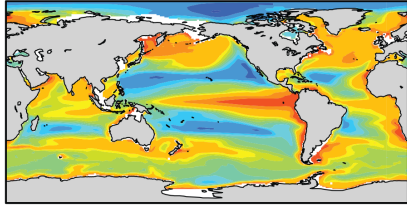

(e) Henson
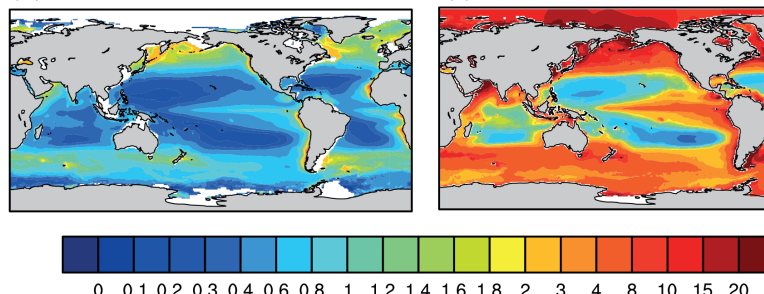

(b) PISCES

(d) REcoM2

(f) Dunne
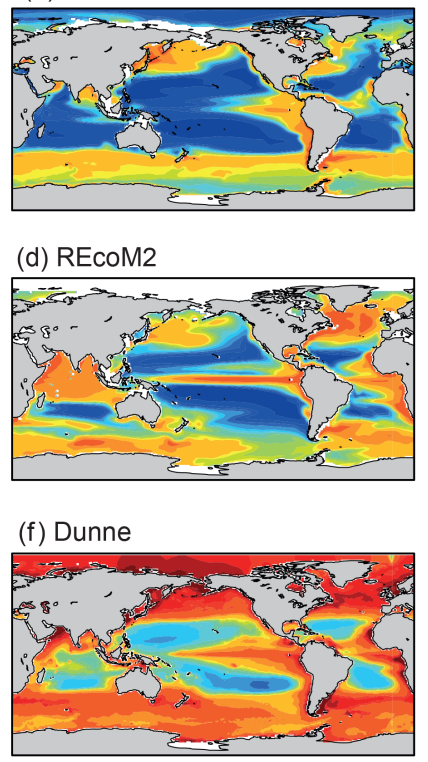

Figure 2. Modelled export production averaged over the 2012-2031 period and observation-based estimates by Dunne et al. (2007) and Henson et al. (2012). The unit is $\mathrm{mol} \mathrm{C} \mathrm{m}^{-2} \mathrm{yr}^{-1}$, note the nonlinear colour scale.

gional comparison between modelled average export production during the 2012-2031 period and satellite-based estimates of annual mean export production by Henson et al. (2012) and Dunne et al. (2007) is given in Fig. 2. A regional comparison of the $e$ ratio can be found in the supplementary material. We have chosen to show two satellitebased estimates to reflect the wide range in current observational estimates. All models capture the general spatial pattern shown in the satellite-based estimates, with low values $\left(<2 \mathrm{~mol} \mathrm{C} \mathrm{m}^{2} \mathrm{yr}^{-1}\right)$ in the subtropical gyres and higher values $\left(>5 \mathrm{~mol} \mathrm{C} \mathrm{m}^{2} \mathrm{yr}^{-1}\right)$ in upwelling regions and in the intermediate and high latitudes, particularly in the North Atlantic and the Southern Ocean. This is reflected in the spatial correlation between modelled and satellite-based export (between 0.35 and 0.57 for all models and all export estimates). In terms of bias, BEC and TOPAZ are closer to the estimates of Dunne et al. (2007) in the low latitudes, while PISCES and REcoM2 are closer to the Henson et al. (2012) estimate. In the high latitudes, all models are closer to the Dunne et al. (2007) estimates. However, the database of ${ }^{234} \mathrm{Th}$-derived export measurements used for the Henson et al. (2012) estimate has a considerable scatter in cold waters, which might explain the discrepancy between the Henson estimate and other satellite-based estimates in the high latitudes (Henson et al., 2011). Finally, all models have a significantly higher spatial variance in export production than the satellite-based estimates. 
Next, we compare the grazing flux in the model output with observationally based estimates of grazing. We use the fraction of NPP that is grazed by microzooplankton reported from Calbet and Landry (2004) and the fraction of NPP that is grazed by mesozooplankton (obtained by dividing the mesozooplankton grazing estimate by Calbet (2001) with the NPP estimate by Behrenfeld and Falkowski (1997)). As grazing is the only loss term for phytoplankton in TOPAZ (besides physical advection/subduction), grazing must balance NPP almost completely in TOPAZ and a comparison with grazing observations has only limited relevance. According to measurements by Calbet (2001) and Calbet and Landry (2004), between 70 and $86 \%$ of NPP is grazed globally by meso- and microzooplankton. BEC and PISCES have values of 77 and $78 \%$ that are within the range of this estimate. PISCES is in terms of microzooplankton grazing at the lower end of the observations but has a twice as high mesozooplankton grazing. In REcoM2, zooplankton grazing is very low and outside of the observational range. Parameters for zooplankton in REcoM2 were chosen to represent copepods, which are relatively slow and inefficient grazers. As a result, grazing rates are lower in REcoM2 than in the other models. NPP therefore has to be nearly balanced by phytoplankton aggregation. The formulation for aggregation is functionally similar to the implicit grazing in TOPAZ, although independent from temperature. Aggregation could therefore be considered to include particle production by microzooplankton grazing. An evaluation of global rates of aggregation is not possible due to the lack of such numbers in the literature. Regional studies suggest that aggregation can contribute up to $30 \%$ of particle formation in the Southern Ocean (Laurenceau et al., 2015) but varies with season (Laurenceau et al., 2015; Ebersbach and Trull, 2008). Aggregation can also dominate particle production in oligotrophic regions (Richardson and Jackson, 2007; Lomas and Moran, 2011).

Finally, we compare the contribution of diatoms to total export within the models and to observational constraints obtained with a nutrient restoring approach (Jin et al., 2006). Jin et al. (2006) combined observations of nitrate, silicic acid and alkalinity with a simple ecological/biogeochemical model to approximate the contribution of diatoms (and other PFTs) to total carbon export. They concluded that diatoms drive 36$43 \%$ of global organic carbon export. We show the contributions of diatoms to particle formation in Table 4 for all four models. However, only in REcoM2 does the value correspond to the diatom contribution to total EP as all particles have the same sinking speed. In the other models, the diatom contribution to total EP is potentially higher than the contribution to particle formation due to different sinking behaviours of the particles. Additionally, it is not possible to determine how much of the POC production via zooplankton mortality stems originally from diatoms. While for most models the POC production via zooplankton mortality is rather low, we might miss up to $16 \%$ of diatom con- tribution to total export in PISCES. REcoM2 simulates diatom contributions close to the Jin et al. (2006) estimate. BEC and TOPAZ are presumably also within this range. PISCES has a rather low diatom contribution to particle formation. However, as particles produced by diatoms have a much higher sinking speed than particles produced by nanophytoplankton in PISCES, the contribution of diatoms to EP might be substantially higher.

\section{Results}

\subsection{Changes in export production}

In the following, we describe the projected changes in export production (EP) and quantify the importance of changes in NPP and $e$ ratio as drivers for EP changes. We then disentangle the effects of changes in particle formation and particle sinking (Sects. 4.2 and 4.3) on the $e$ ratio.

The differences in export production relative to the present state in the individual models between the 2012-2031 average and the 2081-2100 average are shown in Fig. 4. All models project net decreases in EP in the low latitudes $\left(30^{\circ} \mathrm{S}\right.$ to $\left.30^{\circ} \mathrm{N}\right)$ of between -2 and $-25 \%(0.3$ and $0.5 \mathrm{Gt} \mathrm{yr}^{-1}$ ). The region with the strongest disagreement in projected changes between the four models is the eastern tropical Pacific, where BEC projects increases of up to $35 \%\left(0.5 \mathrm{~mol} \mathrm{C} \mathrm{m}^{-2} \mathrm{yr}^{-1}\right)$, PISCES projects strong relative decreases $\left(-40 \%\right.$ or $\left.-0.8 \mathrm{~mol} \mathrm{C} \mathrm{m}^{-2} \mathrm{yr}^{-1}\right)$ and TOPAZ and REcoM2 show a heterogeneous pattern of change. In the Southern Ocean, all models project increases in EP; however, while PISCES only simulates increases south of $60^{\circ} \mathrm{S}$, REcoM 2 and BEC simulate increases also in the intermediate latitudes south of $40^{\circ} \mathrm{S}$ and TOPAZ simulates a heterogenous pattern of changes. The temporal evolution of global EP (and also NPP, $e$ ratio, $p$ ratio and $s$ ratio as described in Sect. 2) is, apart from the inter-annual variability, monotonically and homogeneously decreasing except for REcoM2, which does not show a significant change in global EP. A figure can be found in the supplementary material.

The projected changes in EP are caused by a combination of changes in NPP and changes in the $e$ ratio. To understand the relative importance of these drivers, we decompose the changes in EP with a first-order Taylor decomposition into the sum of the contributions of NPP and $e$ ratio:

$$
\frac{\partial \mathrm{EP}}{\partial t}=\left(\frac{\partial \mathrm{NPP}}{\partial t} \times e \text { ratio }\right)+\left(\frac{\partial e \text { ratio }}{\partial t} \times \mathrm{NPP}\right)+\text { Residual } .
$$

Here, the ratios are calculated first using the full time- and space-resolved model output. The Taylor decomposition is then performed using the ratio fields, we use the difference between the 2012-2031 average and the 2081-2100 average as estimate for the partial derivatives $\frac{\partial}{\partial t}$. Zonal averages of this decomposition are shown in Fig. 5 for each individual model. 
In all four models, the residual is close to zero, allowing us to quantify the relative importance of changes in NPP and changes in $e$ ratio for given changes in EP. In PISCES, the changes in EP are almost exclusively driven by changes in NPP in almost all latitudes. Only in the Southern Ocean do $e$ ratio changes have a more pronounced effect on EP changes. In contrast, the TOPAZ changes in EP are almost exclusively driven by changes in $e$ ratio. Only in the high latitudes do increases in TOPAZ NPP substantially influence the changes in EP. In BEC and REcoM2, $e$ ratio and NPP changes contribute roughly equally to EP changes in the low latitudes, while NPP changes have a somewhat stronger influence in the Southern Ocean.

The changes in NPP in all models used in this study have been extensively described in Laufkötter et al. (2015) and the main drivers and associated uncertainties have been analysed. In this work we focus on the drivers of the changes in the $e$ ratio and refer the reader to Laufkötter et al. (2015) for details on changes in NPP.

\subsection{Particle formation and particle sinking}

To study the drivers of the changes in $e$ ratio, we decompose the $e$ ratio into the $p$ ratio (formation of particle relative to NPP, Eq. 5) and the $s$ ratio (sinking of particles, Eq. 6) as introduced in Sect. 2.1. Average values for the 2012-2031 period of the three efficiencies are shown in Fig. $6 \mathrm{~b}$ and c for the low $\left(30^{\circ} \mathrm{S}\right.$ to $\left.30^{\circ} \mathrm{N}\right)$ and high latitudes $\left(>60^{\circ} \mathrm{S} / \mathrm{N}\right)$. There is a substantial variation in magnitude of all three ratios and also in the relative importance of particle formation and particle sinking, both between different regions and also between different models. The average $e$ ratio varies between 0.2 and 0.38 in the high latitudes and between 0.11 and 0.20 in the low latitudes. In the low latitudes, two models (REcoM2 and PISCES) have a high $p$ ratio ( 0.45 and 0.5 , respectively) and a somewhat lower $s$ ratio (0.3-0.35). The other two models (BEC and TOPAZ) have a low $p$ ratio $(0.1,0.22)$ but a high $s$ ratio ( 0.55 and 0.8 , respectively). In the high latitudes, models simulate $p$ ratios between 0.25 and 0.65 and $s$ ratios between 0.3 and 0.8 .

\subsection{Relative contribution of changes in $p$ ratio and $s$ ratio for changes in $e$ ratio}

To understand the relative importance of changes in $p$ ratio and $s$ ratio for the changes in $e$ ratio, we use another firstorder Taylor decomposition:

$$
\frac{\partial(e \text { ratio })}{\partial t}=\left(\frac{\partial(p \text { ratio })}{\partial t} \times s \text { ratio }\right)+\left(\frac{\partial(s \text { ratio })}{\partial t} \times p \text { ratio }\right)+\text { Residual }
$$

Again the difference between the 2012-2031 average and the 2081-2100 average were used as estimate for the partial derivatives $\frac{\partial}{\partial t}$. The resulting components of the decomposition are shown in Fig. 7. As was the case with EP, the residuals are close to zero in most models, allowing us to separate the relative contributions of changes in $p$ ratio and $s$ ratio to the changes in $e$ ratio. The only exceptions are the low latitudes in PISCES where the residual is almost equally as large as the change in $e$ ratio. Therefore, we cannot quantify the relative contributions of the changes in $p$ ratio and $s$ ratio in PISCES. We do see however that the changes in $p$ ratio and $s$ ratio tend to act in opposite directions in PISCES and therefore partly balance each other. In TOPAZ, changes in $e$ ratio are entirely driven by changes in particle formation. The $s$ ratio remains constant in both the high and low latitudes. Particle production (and $e$ ratio) decreases relatively by about $-7 \%$ in the low latitudes, increases in the Southern Ocean $(+3 \%)$ and decreases in the Arctic $(-12 \%)$. REcoM2 simulates increases in $p$ ratio in both the low and high latitudes. In the low latitudes, the increase is offset by decreases in $s$ ratio, resulting in decreases in $e$ ratio $(-7 \%)$. In contrast, in the high latitudes the $s$ ratio shows rather small changes and particle formation is the main driver for changes in $e$ ratio, leading to an increase in $e$ ratio $(+5 \%)$. BEC projects small decreases in particle formation and $s$ ratio in the low latitudes, resulting in a $5 \%$ decrease in $e$ ratio. In the high latitudes, $p$ ratio decreases substantially $(-20 \%)$ but $s$ ratio strongly increases $(+10 \%)$, resulting in an decrease in $e$ ratio of $-10 \%$.

In summary, changes in $p$ ratio are the main driver of changes in $e$ ratio in TOPAZ, and in REcoM2 and PISCES in the high latitudes. In BEC, in the low latitudes $p$ ratio and $s$ ratio both cause about half of the decrease in $e$ ratio. In all other cases, i.e. in REcoM2 and PISCES in the low latitudes and in BEC in the high latitudes, $p$ ratio and $s$ ratio both contribute significantly to changes in $e$ ratio but tend to have opposite signs.

\subsection{Carbon transfer through the ecosystem}

In this section we build on our quantitative analysis in the last section towards a more mechanistic evaluation of the processes underlying changes in particle formation under climate warming in the various models. First we show the relative importance of the different particle formation processes for total particle formation in different models and regions.

Organic carbon is created during NPP and then routed through the ecosystem following different pathways, partly forming new living biomass, partly formed to dissolved organic carbon, partly being converted back to inorganic carbon during remineralisation processes and partly arriving at the POC pool, some of which is exported from the upper water column. The mechanisms through which sinking particles are produced in models are (i) faecal pellet production during grazing (diatom grazing flux and nano-phytoplankton grazing flux, see Sect. 2.2.2) and (ii) aggregation or mortality of the different phyto- and zooplankton types. In PISCES, particles are additionally formed via the aggregation of dissolved organic carbon. The particle formation is then modelled as the sum of the organic carbon arriving in the sinking particle pool via the different pathways (see Sect. 2 and Fig. 1). 
Figure 8 shows the average efficiency of the particle formation processes (the component summations of the $p$ ratio in Eq. (7), i.e. efficiency of aggregation, faecal pellet production during grazing and zooplankton mortality) during the 2012-2031 average in the four models for the high and low latitudes. The diagram consists of boxes that indicate the structure of the ecosystem by representing the relative contributions of diatoms, nano-phytoplankton and zooplankton to total biomass. Arrows pointing from the biomass components to the POC pool symbolise the efficiency of the respective carbon pathways, i.e. the fraction of NPP routed along that pathway. To enable a comparison between the models, we summarise the two zooplankton types in PISCES in just one zooplankton compartment, and include particle production during grazing of mesozooplankton on microzooplankton in zooplankton mortality. Moreover, PISCES parameterises grazing on particles, and the net effect on particle formation is depicted with the arrow pointing from POC to zooplankton biomass. Aggregation of DOC to sinking particles is only considered in PISCES and is symbolised by an arrow from the left pointing to POC. In TOPAZ, a small fraction of carbon originates from grazing on diazotrophs, and this part has been included in the grazing on nano-phytoplankton. TOPAZ does not simulate any contribution of direct mortality of phyto- or zooplankton to POC.

The models show substantial differences in the efficiency of the different carbon pathways, i.e. the fraction of NPP routed along that pathway.

In TOPAZ only a small fraction of NPP $(8.8-26.5 \%)$ is transformed to sinking particles, and particles are exclusively formed during grazing. In the low latitudes $\left(30^{\circ} \mathrm{S}\right.$ to $\left.30^{\circ} \mathrm{N}\right)$, nano-phytoplankton grazing flux (5.5\% of NPP) is more important than diatom grazing flux (3.3\% of NPP), while in the high latitudes $\left(>50^{\circ} \mathrm{N} / \mathrm{S}\right)$ the diatom grazing flux $(17.3 \%$ of NPP) dominates over nano-phytoplankton grazing flux (9.5\% of NPP).

In REcoM2, phytoplankton aggregation is the dominant mechanism with which particles are formed. In the low latitudes, nano-phytoplankton aggregation constitutes the larger flux $(25.7 \%$ of NPP is routed to POC via nanophytoplankton aggregation), whereas in the high latitudes diatom aggregation constitutes the larger carbon flux ( $45 \%$ of NPP).

In BEC, the nano-phytoplankton grazing flux $(14.0 \%$ of NPP) and to a lesser extent the diatom grazing flux (4.7\% of NPP) are the largest fluxes in the low latitudes. In cold high latitude water diatom aggregation provides the largest carbon flux, about $44 \%$ of NPP is transformed to POC along that pathway.

PISCES has the most complex carbon routing among the models in this study. Zooplankton mortality (including mesozooplankton grazing on microzooplankton) provides the largest flux of carbon to particulate organic carbon in both low and high latitudes (26.4 and $23 \%$ of NPP, respectively). Grazing of nano-phytoplankton is the second largest flux (16\% of NPP in both high and low latitudes). The thirdmost important flux in the low latitudes is aggregation of DOC (12\% of NPP). Aggregation of DOC is only half as strong in the high latitudes $(6.7 \%)$, but diatom aggregation constitutes a large flux ( $9 \%$ of NPP). Finally, in PISCES zooplankton not only produce particles but also graze on particles. This reduction of particles is particularly efficient in the low latitudes, where almost one-third of the formed particles are grazed again, while in the high latitudes less than $10 \%$ of the formed particles are grazed.

\subsection{Changes in carbon transfer through the ecosystem}

The observed changes in $p$ ratio (described in Sect. 4.3) are a result of changes in the efficiency of carbon transfer along the different pathways. The efficiency of carbon transfer is defined as the magnitude of the carbon transfer relative to NPP (Eq. 7). We describe the changes in efficiency of carbon transfer as the change in percentage of NPP [\%NPP] that is transferred along the respective pathway. As an example we describe an increase in efficiency of a pathway from e.g. $12 \%$ of NPP to $14 \%$ of NPP as $+2[\%$ NPP]. The changes in efficiency in each particle formation mechanism are shown in Fig. 8 in the low and high latitudes for all models.

TOPAZ projects small decreases of $-0.55[\% \mathrm{NPP}]$ in particle formation efficiency in the low latitudes and increases of $+0.5[\% \mathrm{NPP}]$ in the high latitudes. As TOPAZ has a low $p$ ratio at the beginning of the simulation $(<10 \%$ of NPP is transformed to particles in the low latitudes), these changes have a significant impact. The changes in export in TOPAZ are almost exclusively driven by changes in $p$ ratio, as both NPP and $s$ ratio stay almost constant (Figs. 5 and 7). The changes in particle formation are caused by higher grazing efficiency of diatoms in the high latitudes and of lower grazing efficiency of both phyto-PFTs in the low latitudes, in both regions following changes in diatom and small phytoplankton biomass (Fig. 8). Mortality and aggregation are not considered in TOPAZ.

REcoM2 projects increases in $p$ ratio of $+0.8[\% \mathrm{NPP}]$ and $+3[\% \mathrm{NPP}]$ in the low latitudes and Southern Ocean, respectively (Fig. 8). Note that REcoM2 does not simulate the Arctic, therefore we discuss results for the Southern Ocean instead of the high latitudes. The changes in both regions are almost exclusively composed of changes in aggregation, reflecting the high importance of these carbon pathways in this model (Fig. 8). The changes in aggregation are mostly driven by changes in diatom and nano-phytoplankton biomass. As discussed in Sect. 3, aggregation in REcoM2 can be considered to include contributions of microzooplankton grazing by model design. 


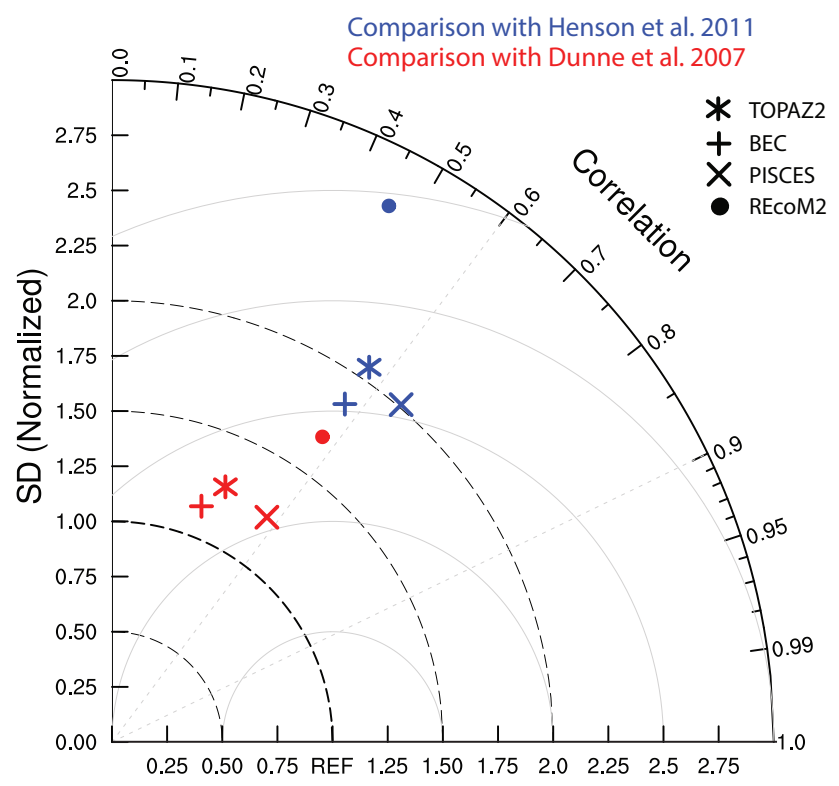

Figure 3. Taylor diagram comparing modelled export production averaged over the 2012-2031 period with satellite-based estimates by Dunne et al. (2007) and Henson et al. (2012). The angle describes the correlation between model and satellite-based estimate, the distance from the origin is the normalised standard deviation and the distance from the point REF is the root mean squared error.

BEC projects decreases in $p$ ratio in the high latitudes ( $-5[\% \mathrm{NPP}])$, mainly through a decrease in efficiency of diatom and nano-phytoplankton aggregation $(-3.5[\% \mathrm{NPP}]$, $-1.5[\% \mathrm{NPP}]$, respectively, caused by lower biomass in large regions of the high latitudes. The $-0.6[\% \mathrm{NPP}]$ decrease in the $p$ ratio in the low latitudes is caused by lower diatom grazing efficiency and diatom aggregation efficiency, caused by decreases in diatom biomass (Fig. 8).

PISCES projects strong decreases in $p$ ratio in the high latitudes $(-7.5[\% \mathrm{NPP}])$ and increases in the low latitudes $(+0.5[\% \mathrm{NPP}]$, Fig. 8). In the high latitudes, decreases in grazing on nano-phytoplankton and microzooplankton mortality are responsible for the net changes. In the low latitudes the strongest changes in particle formation efficiency are (i) due to a more efficient aggregation of DOC to sinking particles $(+1[\% \mathrm{NPP}])$ and increases in efficiency of zooplankton mortality $(+0.5[\% \mathrm{NPP}])$, and (ii) in relation to NPP more particles are grazed $(-1[\% \mathrm{NPP}])$, which partly compensates the aforementioned increases (Fig. 8).

In summary, two models (REcoM2 and PISCES) simulate an increase in $p$ ratio in the low latitudes, however for different reasons. In REcoM2, increases in small phytoplankton biomass lead to stronger and more efficient small phytoplankton aggregation. In PISCES, the changes in $p$ ratio are mainly caused by strong decreases in NPP, while aggregation of DOC to POC and also mesozooplankton mortality only slightly decrease and therefore relative to NPP increase. BEC and TOPAZ simulate decreases in $p$ ratio in the low lat- itudes, driven by decreases in diatom biomass. In the Southern Ocean, TOPAZ and REcoM2 simulate increases in $p$ ratio, driven by increases in diatom biomass. BEC and PISCES simulate decreases in $p$ ratio, in both models as a net effect of regional biomass decreases.

\subsection{Changes in particle sinking efficiency ( $s$ ratio)}

Independent of the specific model parameterisations, the $s$ ratio is affected by the depth at which particle formation occurs. For example, if the particle formation shifts towards the surface, the particles have to overcome a longer distance during which they are prone to remineralisation processes and the $s$ ratio will decrease. We did not observe significant changes between the 2012-2031 average and the 2081-2100 average in the depth distribution of biomass or particle formation in any of the four models (data not shown). We therefore assume that changes in vertical biomass distribution do not play a significant role for the simulated changes in $s$ ratio.

In TOPAZ, the $s$ ratio does barely change over time in both the high and low latitudes (Fig. 7a). The remineralisation is independent of temperature in TOPAZ, which might partly explain why the $s$ ratio is not changing. Additional implemented processes that might affect the $s$ ratio are changes in ballasting of particles with silicate and calcium carbonate. There are decreases in exported $\mathrm{Si}: \mathrm{POC}$ and $\mathrm{CaCO}_{3}: \mathrm{POC}$ (not shown), but we hypothesise that because of the high $s$ ratio in TOPAZ at the beginning of the simulation $(>70 \%$ in both high and low latitudes), the changes in ballasting are comparatively inconsequential.

REcoM2 shows decreases in $s$ ratio in both the high and low latitudes (Fig. 7b). In REcoM2, changes in the $s$ ratio can only be caused by changes in temperature, with warmer temperatures leading to a stronger remineralisation and less efficient sinking ( $Q_{10}$ changes with increasing temperature but is roughly 1.75). REcoM2 does not include a ballasting effect or parameterises other influences of the ecosystem composition on the $s$ ratio. We conclude that the observed decreases in $s$ ratio in the low latitudes reflect increases in remineralisation caused by the warming of the water column $\left(+2{ }^{\circ} \mathrm{C}\right.$ on average in the upper $100 \mathrm{~m}$ ).

BEC simulates decreases in $s$ ratio in the low latitudes but substantial increases in the high latitudes (Fig. 7c). In $\mathrm{BEC}$, the $s$ ratio depends on the composition of the ecosystem, as diatoms produce particles ballasted with silicate and a fraction of nano-phytoplankton is modelled as calcifiers, which produce particles ballasted with $\mathrm{CaCO}_{3}$. Both silicate and $\mathrm{CaCO}_{3}$ have a longer remineralisation length scale than unballasted organic material. In the low latitudes, decreases in $s$ ratio are responsible for half of the changes in $e$ ratio. On the one hand, the diatom relative contribution to biomass de- creases resulting in a lower $\mathrm{Si}$ : POC ratio, which tends to decrease the $s$ ratio, on the other hand the ratio of exported $\mathrm{CaCO}_{3}$ : $\mathrm{POC}$ increases, which tends to increase the $s$ ratio. As the $s$ ratio decreases we conclude that the diatom 
BEC

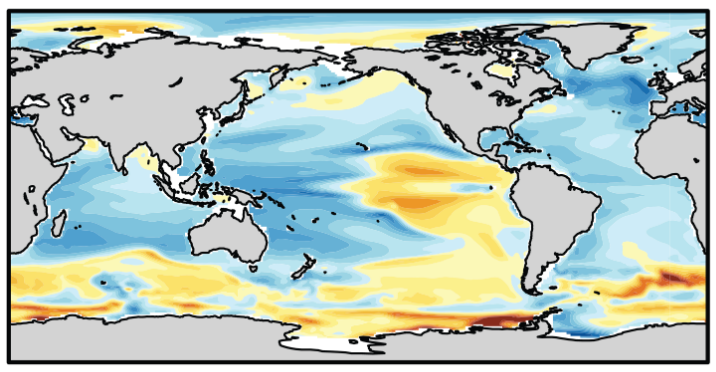

TOPAZ

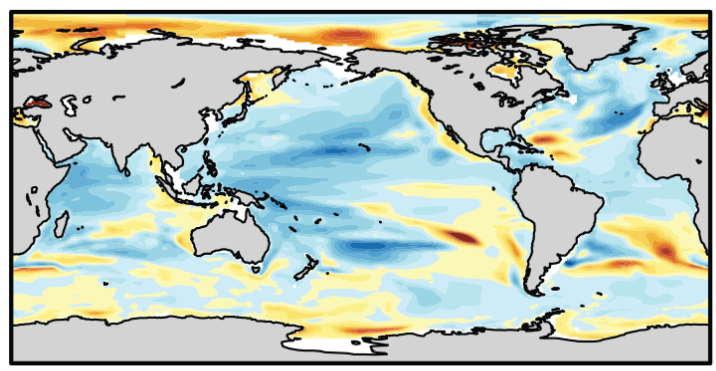

PISCES

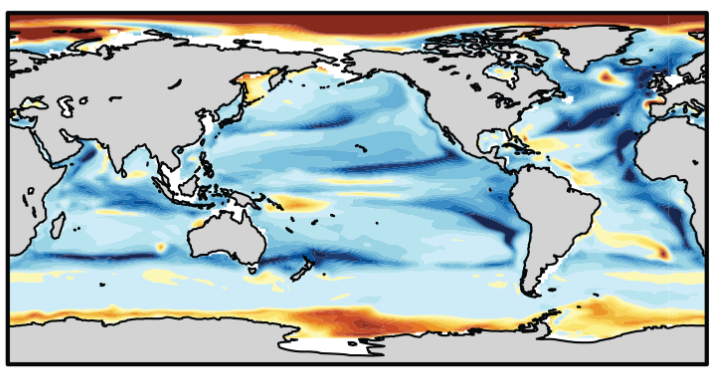

REcoM2

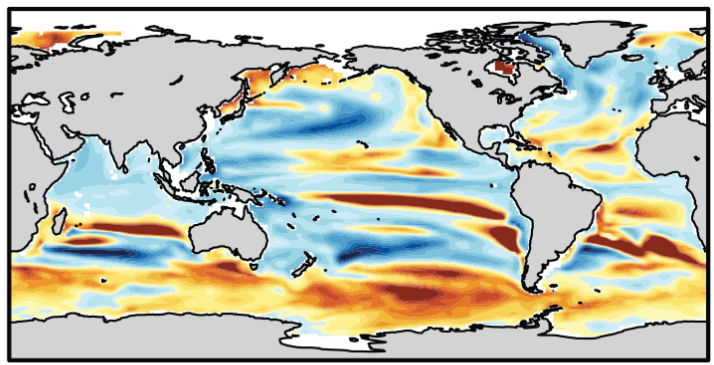

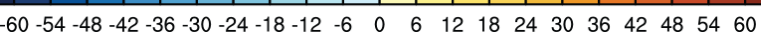

Figure 4. Relative changes in export production through the $100 \mathrm{~m}$ depth level between the 2012-2031 average and the 2081-2100 average in all models in \%.

effect dominates in the low latitudes. In the high latitudes, there is no significant change in $\mathrm{Si}$ : $\mathrm{POC}$ export but a strong increase in the ratio of exported $\mathrm{CaCO}_{3}$ : $\mathrm{POC}$, i.e. a shift towards a community more dominated by calcifiers, resulting in a strong increase in $s$ ratio $(+10 \%)$. However, despite the strong increase in $s$ ratio the $e$ ratio mostly follows the decrease in $p$ ratio and the residual of the Taylor decomposition are quite large. These results suggest that ballasting has a moderate impact on $e$ ratio in BEC.

PISCES simulates decreases in $s$ ratio in both the high and low latitudes (Fig. 7 d). PISCES has a temperaturedependent remineralisation of organic carbon $\left(Q_{10}=1.9\right)$. In addition, two particle size classes with different sinking velocities are considered. Mesozooplankton and diatoms produce large, faster sinking particles while microzooplankton and nano-phytoplankton tend to contribute to the smaller and less rapidly sinking particle class. The sinking efficiency is therefore directly affected by temperature, with warmer temperatures leading to a lower sinking efficiency. It is also affected by the relative contribution of small and large particles to the total sinking particle pool. PISCES simulates temperature increases by $2{ }^{\circ} \mathrm{C}$ in both the high and low latitudes. The particle composition changes from $5 \%$ large particles to $4 \%$ large particles in the low latitudes. Both temperature and changes in particle composition contribute to a lower sinking efficiency; however, the relative importance of the two drivers is not distinguishable from our results.
In summary, the $s$ ratio stays constant in TOPAZ and does not affect changes in $e$ ratio. The decreases in $s$ ratio in REcoM2 are driven by warming-induced increases in remineralisation rates. In BEC, the decreases in $s$ ratio in the low latitudes are a net result of decreases in particles ballasted with silicate, counteracting increases in particles ballasted with $\mathrm{CaCO}_{3}$. The increases in $s$ ratio in the high latitudes are driven by increases in $\mathrm{CaCO}_{3}$ ballasting, but have only a moderate impact on $e$ ratio changes. In PISCES, the decreases in $s$ ratio in all latitudes are driven by both stronger remineralisation and a shift towards smaller particles.

\section{Discussion}

The model projections analysed in this work suggest decreases in future export production between -1 and $-12 \%$, composed of decreases in the low latitudes that are in some models partly balanced by increases in the high latitudes. Both magnitude and spatial distribution of the export changes are in agreement with previous studies (Steinacher et al., 2010; Bopp et al., 2013; Hauck et al., 2015). However, previous authors have mostly focused on the drivers of NPP changes to explain changes in EP (Steinacher et al., 2010; Hauck et al., 2015). Our analysis reveals that the relative importance of $e$ ratio and NPP changes on EP varies between models, with one model showing EP changes almost independent from $e$ ratio changes on larger scales (PISCES), two 

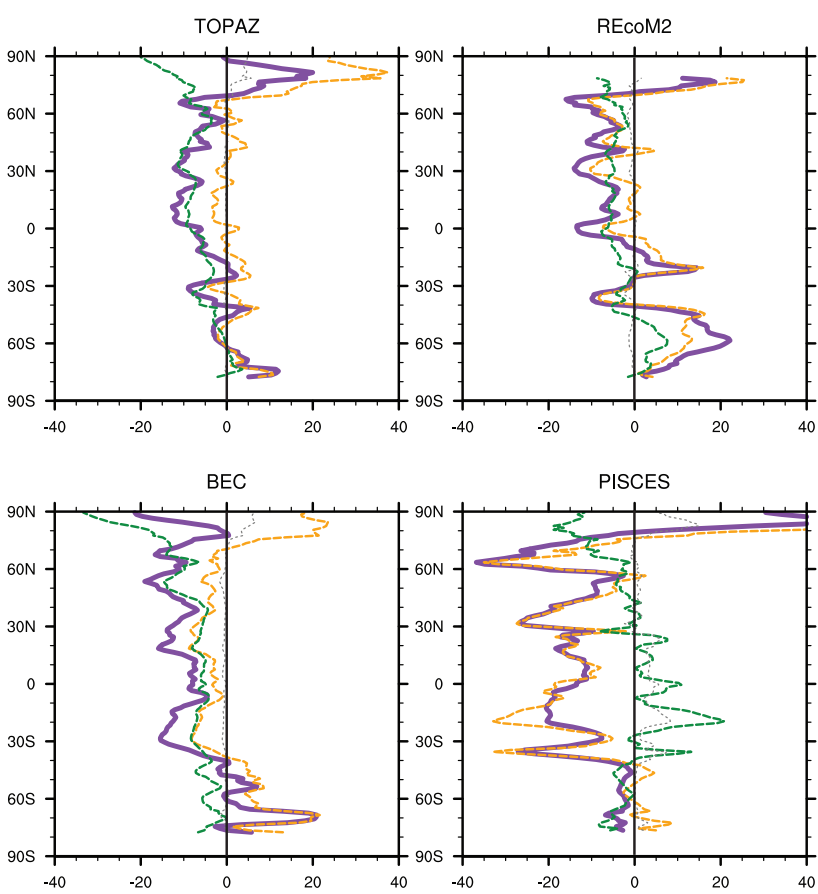

Figure 5. First-order Taylor decomposition of percentaged changes in zonal mean export production (purple) into the weighted changes in NPP $\left(\frac{\delta \mathrm{NPP}}{\delta t} \times e\right.$ ratio, orange $)$, and in $e$ ratio $\left(\frac{\delta e \text { ratio }}{\delta t} \times \mathrm{NPP}\right.$, green). Residuals are shown in grey. (a) Illustration of ratios

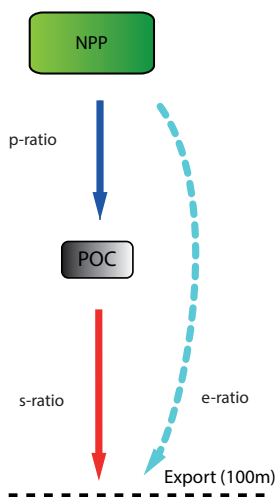

(b) High latitudes

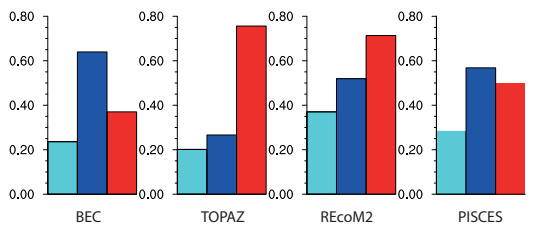

(c) Low latitudes

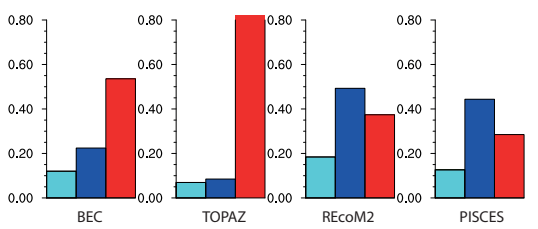

Figure 6. (a) Illustration of $p$ ratio, $s$ ratio and $e$ ratio (as defined in Eqs. 4, 5 and 6). The product of the $p$ ratio and the $s$ ratio results in the $e$ ratio. The colours of the arrows correspond with the colours in the bar chart. (b) and (c) comparison of the temporal (2012-2031) and spatial mean $e$ ratio (cyan), $p$ ratio (blue) and $s$ ratio (red) in the high and low latitudes, respectively, for the full simulation period and for all models.

models showing an equal importance of NPP and $e$ ratio changes for EP changes (BEC and REcoM2) and one model simulating EP changes that are almost exclusively caused by changes in the $e$ ratio (TOPAZ). We conclude that the $e$ ratio changes, i.e. the way organic carbon is routed and
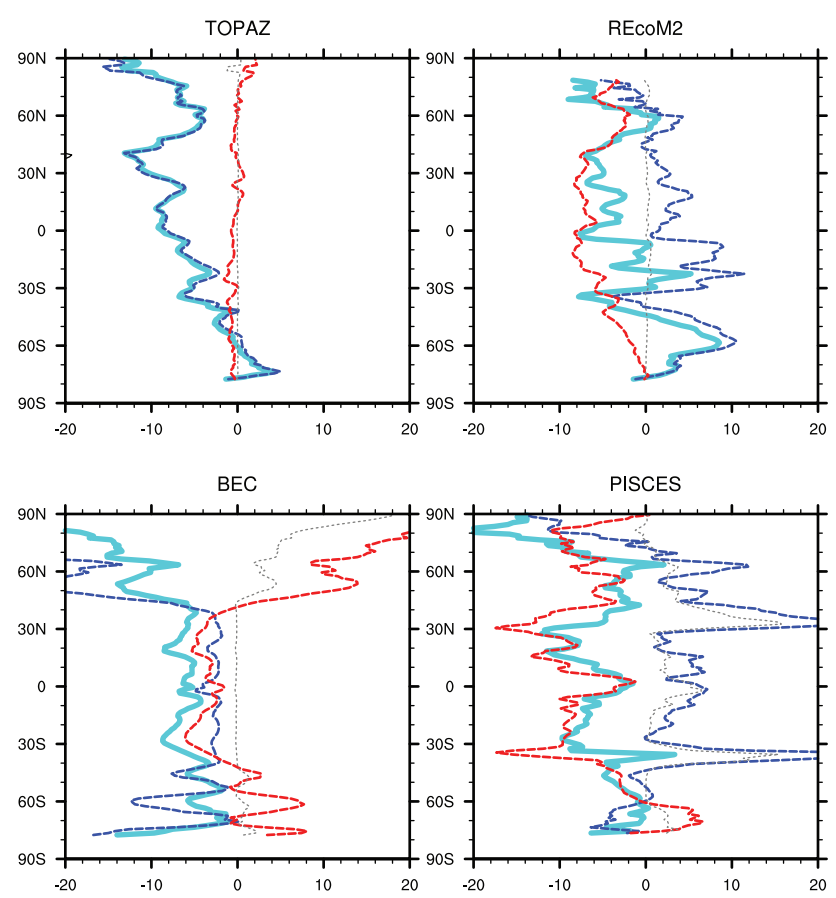

Figure 7. First-order Taylor decomposition of percentaged changes in zonal mean $e$ ratio (cyan) into the weighted changes in $p$ ratio $\left(\frac{\delta p \text { ratio }}{\delta t} \times s\right.$ ratio, blue $)$, and in $s$ ratio $\left(\frac{\delta s \text { ratio }}{\delta t} \times p\right.$ ratio, red $)$. Residuals are shown in grey.

transformed by the upper ocean ecosystem, are an important drivers for EP changes that always needs to be included in discussions of export changes.

\subsection{Drivers of $e$ ratio changes in previous studies and the role of diatoms}

The responses of the $e$ ratio to future climate change have been analysed using earlier versions of PISCES (Bopp et al., 2005) and BEC (Marinov et al., 2013). Although the studies differ in forcing $\left(1 \% \mathrm{CO}_{2}\right.$ increase per year in Bopp et al. (2005), SRES A2 in Marinov et al. (2013)), both studies simulated decreases in the $e$ ratio within the next 100 years. In both cases, a decrease in relative diatom contribution to total biomass has been reported as the main driver for the decrease in $e$ ratio, mainly because (i) a shift towards nano-phytoplankton is associated with lower particle formation rates (lower $p$ ratio) and (ii) nano-phytoplankton produce smaller particles, which are not ballasted with silicate, leading to slower particle sinking (lower $s$ ratio). However, both studies base their arguments on global correlations between diatom fraction and $e$ ratio. Our analysis of the $p$ and $s$ ratio allows for a more mechanistic understanding of the effect of diatom fraction changes on $e$ ratio changes.

While the diatom fraction decreases in all models in the low latitudes (not shown), the $p$ ratio increases in both REcoM2 and PISCES, showing that a decrease in diatom frac- 

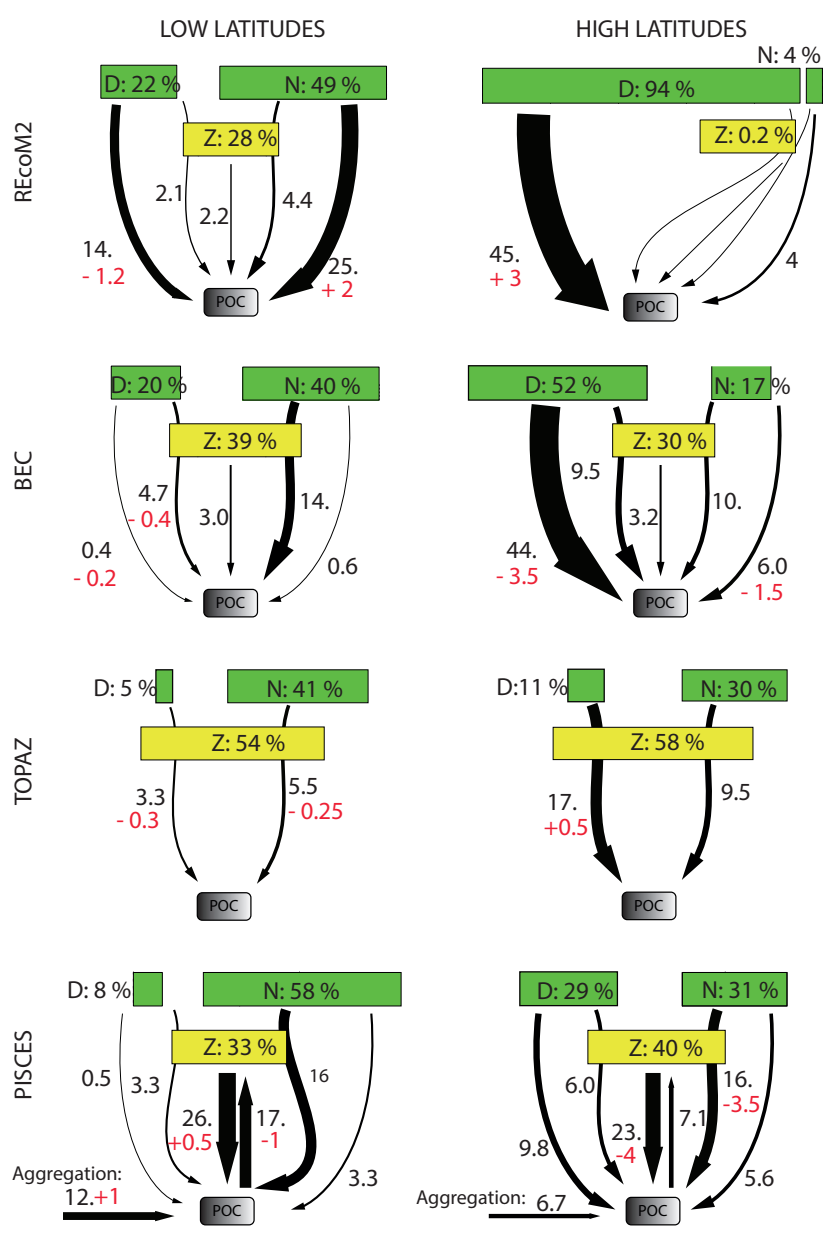

Figure 8. Diagrammatic depiction of the ecosystem structure and the particle formation mechanisms in the low latitudes $(<$ $\pm 30^{\circ} \mathrm{N} / \mathrm{S}$, on the left) and in the high latitudes $\left(>60^{\circ} \mathrm{N} / \mathrm{S}\right)$, on the right. Shown are the 2012-2031 average (black numbers) and the changes between the 2012-2031 period and the 2081-2100 period (red numbers). The model REcoM2 does not simulate the Arctic, the high latitude results therefore represent the Southern Ocean only. The green boxes show diatom (marked with D) and nano-phytoplankton $(\mathrm{N})$ biomass, the yellow boxes $(\mathrm{Z})$ zooplankton biomass, all given in percent of total biomass. The arrows within the panels denote from left to right: diatom aggregation, grazing on diatoms, zooplankton mortality (including grazing of mesozooplankton on microzooplankton in PISCES), grazing on nanophytoplankton and nano-phytoplankton aggregation. PISCES additionally includes DOC aggregation. The fluxes are given in percent of total NPP. The sum of all fluxes results in the $p$ ratio of a model. The arrows depicting the largest fluxes are marked in red and the changes in these fluxes are given in percent of total NPP. For more details see text.

tion does not necessarily lead to a lower $p$ ratio. Diatom fraction has a clear mechanistic link with changes in particle formation only in models where either diatom fraction is high (BEC) or diatoms are highly efficient at particle formation (TOPAZ). In terms of sinking speed, changes in the diatom fraction do not affect the $s$ ratio in two models (TOPAZ, REcoM2) but decrease the $s$ ratio in BEC. In PISCES it is unclear to what extent the observed changes are driven by temperature effects or lower diatom fraction. In the Southern Ocean, diatoms are more abundant and all models project increases in the diatom fraction. Yet, the $e$ ratio decreases in BEC and PISCES, showing that models currently do not agree on the effects of diatom fraction changes on $e$ ratio changes. These results indicate that the effects of changes in diatom fraction on $e$ ratio changes might be of lower importance than generally assumed, potentially because other factors such as changes in temperature, ballasting with $\mathrm{CaCO}_{3}$ (see e.g. Kvale et al., 2015) or aggregation effects could be at least equally important.

\subsection{Relative contribution of plankton functional types to particle export}

The relative contribution of plankton functional types to particle export is observationally weakly constrained, and there are only few theoretical estimates to compare our results with. In a nutrient restoring approach, Jin et al. (2006) estimated that carbon export is dominated by large phytoplankton ( $73 \%$ globally), $43 \%$ thereof driven by diatoms. The remaining $27 \%$ were estimated to be driven by small phytoplankton, thereof $11 \%$ by coccolithophores. A direct comparison with our results is difficult as the contribution of the different PFTs to total EP is not known in the investigated models. However, the inter-model differences in both diatom contribution to biomass and also diatom contribution to particle formation point to substantial inter-model differences in diatom contribution to carbon export. Furthermore, most models do not differentiate between large phytoplankton (e.g. dinoflagellates and other large eukaryotes) and diatoms (with TOPAZ being the only exception). The lack of a non-diatom large phytoplankton type forces the models to switch to small phytoplankton as soon as silicate is depleted; therefore, they cannot reproduce the pattern suggested in Jin et al. (2006). Overall, the simulation of diatom distribution is currently afflicted with high uncertainties, and consequentially model agreement on silicate-limited regions is low. Also, the correlations of modelled silicate with silicate observations are poor (Laufkötter et al., 2015).

Measurements of the relative contribution of phytoand zooplankton types to the sinking particle pool are sparse. In the low latitudes, aggregation of pico- and nanophytoplankton has until recently been assumed negligible and consequentially these fluxes constitute at the most a few percent of total EP in the models in our study, with REcoM2 being the only exception. However, significant export production by pico- and nano-plankton has been inferred from inverse analysis (Richardson and Jackson, 2007) and subsequently contributions of pico- and nano-plankton to total export of up to $33 \pm 27 \%$ have been measured by Lomas and Moran (2011). In the Southern Ocean, phytodetrital aggre- 
gates can contribute up to $30 \%$ of total carbon export (measured during the initiation of the spring bloom by Laurenceau et al. (2015)). The available observations suggest that the contributions of phyto- and zooplankton to particle formation are both temporally and spatially variable in the Southern Ocean (Ebersbach and Trull, 2008; Bowie et al., 2011; Ebersbach et al., 2011; Smetacek et al., 2012; Quéguiner, 2013; Laurenceau et al., 2015), making it difficult to constrain the contribution of phytoplankton aggregation to particle formation on coarser temporal and spatial scales. Recently published metagenomic data and data on particle size distributions might be an important step forward in elucidating the complicated interplay between different members of the planktonic ecosystem and the carbon flux to depth (Guidi et al., 2016).

In terms of zooplankton grazing and faecal pellet production, Calbet and Landry (2004) suggested that about $70 \%$ of primary production is grazed by microzooplankton in tropical and subtropical waters and about $65 \%$ in the polar oceans. Mesozooplankton grazing has been estimated to amount up to $12 \%$ of global NPP by Calbet (2001). Besiktepe and Dam (2002) estimated that $31 \%$ of the material grazed by mesozooplankton is routed to particulate egestion. Stoecker (1984) suggested $13 \%$ of material grazed by microzooplankton ends up as sinking particles. In models, the unassimilated faecal material is sometimes modelled as a constant fraction of grazed material equal for each phytoor zooplankton type (PISCES, REcoM2), sometimes using varying fractions depending on phytoplankton type (BEC, TOPAZ) and temperature (TOPAZ). Overall, the fraction of the grazed material that is routed to POC varies between 0.18 (grazed nano-phytoplankton in TOPAZ at $0^{\circ} \mathrm{C}$ ) and 0.93 (grazed diatoms in TOPAZ at $0^{\circ} \mathrm{C}$ ) in models. Improved observational constraints for the fraction of grazed material that becomes faecal pellets will be critical to improve the simulation and projected changes of the $e$ ratio.

Phytoplankton aggregation is thought to represent the most efficient way of exporting carbon as routing through each additional trophic level causes losses of organic carbon via respiration (Alldredge and Jackson, 1995). In models, phytoplankton aggregation is assumed to be independent of temperature and it usually depends only on phytoplankton concentration. In an aggregation-dominated ocean the efficiency of particle formation would be mostly driven by phytoplankton biomass levels and might decrease with decreasing biomass levels. In contrast, zooplankton growth and grazing depend exponentially on temperature, with a potentially higher temperature dependence than phytoplankton growth (López-Urrutia et al., 2006). If particles mostly stem from zooplankton in the real ocean, particle production might become more efficient because of higher grazing pressure, or less efficient because of a higher zooplankton respiration. Moreover, the efficiency of particle formation might be affected by interaction between zooplankton types of different trophic levels. Therefore, the direction of changes in $p$ ratio depends on the processes controlling how particles are formed, and models can only project realistic $e$ ratio changes if they capture the processes dictating how particles are formed. However, the most important processes, their magnitude and variability have not yet been identified, and observations to constrain parameters of potential candidate processes are sparse. Our results show that models currently differ strongly in their dominant particle formation processes, making their $e$ ratio projections highly uncertain.

\subsection{Reasons for differences in $e$ ratio projections}

Comparing the differences in $e$ ratio projections with the differences in NPP projections, we find that the main reasons for differences in NPP projections are different parameterisations of the same processes, in particular their sensitivity towards nutrient availability and temperature (Laufkötter et al., 2015). In terms of projections of $e$ ratio, we find that uncertainty arises from both the difference in the number of processes included in models and from the parameterisations of said processes. One reason for the uncertainties in $e$ ratio projections are the uncertainties in plankton community composition and the fraction of biomass that is aggregated/grazed. Observational data are urgently needed to better constrain the models. In terms of particle formation, processes that potentially cause strong carbon fluxes but are not included in most models are the aggregation of DOC, grazing on particles and explicit particle production by zooplankton of higher trophic levels. Observational efforts to constrain these processes will strongly improve $e$ ratio projections. In terms of particle sinking, some models parameterise different particle size classes, others ballasting with silicate, calcite or aragonite, and the inclusion of these different processes leads to very different responses of particle sinking to changes in ecosystem structure. As an example, a change in plankton composition towards smaller phytoplankton will decrease particle size and sinking speed in PISCES, might (depending on region) increase the remineralisation length scale in BEC because of stronger ballasting with $\mathrm{CaCO}_{3}$, show only small effects in TOPAZ as ballasting with silicate and aragonite (associated with diatoms and large phytoplankton) switches to ballasting with calcite (associated with nano-phytoplankton) and will not affect the $s$ ratio in REcoM2.

A community effort to identify and constrain the most important processes and subsequent model development, such that a similar set of processes is included in all models used for $e$ ratio/EP projections, would make the models more comparable and would allow for a better quantification of the uncertainty and importance of the respective processes. 


\section{Conclusions}

In this work we analyse future projections of changes in export production and $e$ ratio in four marine ecosystem models under the RCP8.5 scenario. We show that $e$ ratio changes and NPP changes can be equally important for changes in export production, and that the processes causing the $e$ ratio changes differ strongly between models. The most uncertain process among the models analysed in this work is in particle formation ( $p$ ratio), where models do not even agree on the direction of change. Mechanistically, this is caused by large differences in the inclusion and parameterisation of phytodetritus, zooplankton faecal pellet production, zooplankton mortality losses and particle aggregation dynamics on particle formation rates. Additionally, models implement different sinking processes that are governed by different drivers. Warminginduced increases in remineralisation rates could not be fully disentangled from ballasting effects or changes in particle size distribution in several models. Simulations in which one or several of these processes are held constant would help to further explore the ballasting and temperature effects and improve our understanding of the role of temperature for the changes in $e$ ratio. Our analysis focuses on the differences in the biogeochemistry models, a detailed analysis of the role of circulation is beyond the scope of this work. We acknowledge that changes in ocean circulation play an important role in driving future export production, both on large and small scales (e.g. Najjar et al., 2007; Omand and Mahadevan, 2015). Future work should try to quantify the differences in physics, for instance by using modelling frameworks in which one biogeochemistry model can be coupled to different circulation models (e.g. Allen et al., 2010). We conclude that the current projections of export production and $e$ ratio suffer from high uncertainties, particularly at the regional scale. In order to increase the reliability of $e$ ratio projections, a concerted effort including observations and targeted laboratory studies of plankton community structure, particle composition and sinking behaviour, particle aggregation rates, ballasting effects and grazing controls to support further model development and a rigorous model evaluation will be needed.

\section{Data availability}

Our analysis compares output of four different marine biogeochemistry models. Two of the simulations (models BEC and REcoM2) were obtained from the "MARine Ecosystem Model Intercomparison Project" (MAREMIP; http://pft.ees. hokudai.ac.jp/maremip/index.shtml; Vogt et al. (2013); Sailley et al. (2013); Hashioka et al. (2013). The other two simulations (PISCES and TOPAZ) are ensemble members of the Coupled Model Intercomparison Project 5 (CMIP5 Taylor et al., 2012) runs of these models. The data can be obtained by contacting the respective modeling centers (see references in Table 1). 


\section{Appendix A}

In the following, we give the equations and parameters governing particle formation, i.e. grazing of p-PFT $i\left(G_{i}\right)$ and particle formation during grazing $\left(G_{i}^{\mathrm{POC}}\right)$, phytoplankton aggregation $\left(A_{i}\right)$ and phyto- and zooplankton mortality $\left(M_{i}\right)$.

\section{A1 BEC}

Particle formation $=A_{\text {nano }}+M_{\text {nano }}^{\mathrm{POC}}+A_{\text {diat }}+M_{\text {diat }}^{\mathrm{POC}}+$

$A_{\text {nano }}=\min \left\{\begin{array}{l}G_{\text {nano }}^{\mathrm{POC}}+ \\ a_{\text {nano }}^{\max } \times P_{\text {nano }} \\ p_{\text {nano }} \times P_{\text {nano }}^{2},\end{array}\right.$

$A_{\text {diat }}$ is calculated analog.

$G_{\text {nano }}^{\mathrm{POC}}=G_{\text {nano }} \times \max \left\{\begin{array}{l}f_{\mathrm{graz}}^{\mathrm{CaCO}, \mathrm{POC}} \times Q_{\mathrm{nano}}^{\mathrm{CaCO} 3} \\ \min \left\{\begin{array}{l}e_{\text {nano }}^{\mathrm{POC}} \times P_{\text {nano }} \\ f_{\text {grazo }}^{\text {nano }} \text { POC }\end{array}\right.\end{array}\right.$

$G_{\text {diat }}^{\mathrm{POC}}=f_{\text {graz }}^{\text {diat, } \mathrm{POC}} \times G_{\text {nano }}$,

$G_{\text {nano }}=u_{\max }^{\text {nano }} \times \operatorname{Tf} \times \frac{P_{\text {nano }}^{2}}{P_{\text {nano }}^{2}+g^{2}} \times Z$,

$G_{\text {diat }}=u_{\max }^{\text {diat }} \times \operatorname{Tf} \times \frac{P_{\text {diat }}^{2}}{P_{\text {diat }}^{2}+g^{2} \times f_{z}^{\text {diat }}} \times Z$,

$M_{\text {nano }}^{\mathrm{POC}}=Q_{\text {nano }}^{\mathrm{CaCO}} \times m_{\text {nano }} \times P_{\text {nano }}$,

$M_{\text {diat }}^{\mathrm{POC}}=f_{\text {diat loss }}^{\mathrm{POC}} \times m_{\text {diat }} \times P_{\text {diat }}$,

$F_{Z}^{\mathrm{POC}}=\frac{f_{\text {zloss }}^{\text {nano, } \mathrm{POC}} \times G_{\text {nano }}+f_{\text {zloss }}^{\text {diat,POC }} \times G_{\text {diat }}+f_{\text {zloss }}^{\text {diaz,POC }} \times G_{\text {diaz }}}{G_{\text {nano }}+G_{\text {diat }}+G_{\text {diaz }}}$,

$M_{\mathrm{zoO}}^{\mathrm{POC}}=F_{Z}^{\mathrm{POC}} \times\left(m_{\mathrm{z}} Z+p_{\mathrm{z}} Z^{2}\right)$,

$G_{\mathrm{diaz}}=u_{\max }^{\mathrm{diaz}} \times \operatorname{Tf} \times \frac{P_{\mathrm{diaz}}^{2}}{P_{\mathrm{diaz}}^{2}+g^{2}} \times Z$.

\section{A2 PISCES}

Particle formation equations:

small particle formation $=G_{\text {micro } \rightarrow \text { nano }}^{\mathrm{POC}}+G_{\text {micro } \rightarrow \text { diat }}^{\mathrm{POC}}$

$$
+A_{\text {nano }}^{\mathrm{POCs}}+M_{\text {nano }}^{\mathrm{POCs}}+M_{\mathrm{diat}}^{\mathrm{POC}}+M_{\text {micro }}+A_{\mathrm{DON} \rightarrow \mathrm{POCs}},
$$

large particle formation $=G_{\text {meso } \rightarrow \text { nano }}^{\mathrm{POCs}}+G_{\text {meso } \rightarrow \text { nano }}^{\mathrm{POC}}$

$$
\begin{aligned}
& +G_{\text {meso } \rightarrow \text { micro }}^{\mathrm{POC}}+M_{\text {meso }}+A_{\text {nano }}^{\mathrm{POCl}}+M_{\text {nano }}^{\mathrm{POCl}}+M_{\text {diat }}^{\mathrm{POCl}} \\
& +A_{\text {diat }}^{\mathrm{POCl}}+A_{\mathrm{DON} \rightarrow \mathrm{POCl}}+A_{\text {POCs. } \rightarrow \text { POCl }} .
\end{aligned}
$$

Plankton aggregation and mortality equations:

$$
\begin{aligned}
M_{\text {nano }}^{\text {POCs }} & =f_{\text {mort }}^{\text {nano, POCs }} \times m_{\text {nano }} \times \frac{P_{\text {nano }}}{K_{\mathrm{M}}+P_{\text {nano }}} \times P_{\text {nano }}, \\
& M_{\text {nano }}^{\text {POCl analog },} \\
M_{\text {diat }}^{\text {POCs }}= & f_{\text {mort }}^{\text {diat,POCs }} \times m_{\text {diat }} \times \frac{P_{\text {diat }}}{K_{\mathrm{M}}+P_{\text {diat }}} \times P_{\text {diat }},
\end{aligned}
$$

$M_{\text {diat }}^{\mathrm{POCl}}$ analog,

$$
\begin{aligned}
& A_{\text {nano }}^{\mathrm{POCs}}=f_{\text {agg }}^{\text {nano,POCs }} \times s_{h} \times p_{\text {nano }} \times P_{\text {nano }}^{2}, A_{\text {nano }}^{\mathrm{POCl}} \text { analog }, \\
& A_{\text {diat }}=f_{\text {agg }}^{\text {diat,POCl }} \times s_{h} \times p_{\text {diat }} \times P_{\text {diat }}^{2}, \\
& M_{\text {micro }}=m_{\text {micro }} \times T_{f} \times \frac{Z_{\text {micro }}}{K_{\mathrm{M}}+Z_{\text {micro }}} \times Z_{\text {micro }}
\end{aligned}
$$
$\times$ denitrification factor,

$$
\begin{aligned}
M_{\text {meso }}= & m_{\text {meso }} \times T_{f} \times \frac{Z_{\text {meso }}}{K_{\mathrm{M}}+Z_{\text {meso }}} \times Z_{\text {meso }} \\
& \times \text { denitrification factor }+p_{\text {meso }} \times Z_{\text {meso }} .
\end{aligned}
$$

Here, $s_{h}$ denotes the shear rate, which is set to $\left[1 s^{-1}\right]$ in the mixed layer and 0.01 elsewhere. The denitrification factor has values between 0 and 1 and is calculated out of oxygen using the following formula:

denitrification factor $=0.4 \times\left(6 . e^{-6}-\mathrm{O}_{2}\right) /\left(1 . e^{-6}+\mathrm{O}_{2}\right)$.

Grazing equations:

$$
\begin{aligned}
G_{\text {micro }} \rightarrow \text { nano } & =f_{\text {graz }}^{\mathrm{POC}} \times G_{\text {micro } \rightarrow \text { nano }}, \\
G_{\text {micro }} & \text { nano }=u_{\text {max }}^{\text {micro } \rightarrow \text { nano }} \times T_{f} \\
& \times \frac{\Psi_{\text {nano }}^{\text {micro }} P_{\text {nano }}}{\sum_{I} \Psi_{\text {nano }}^{\text {micro }} \times I} \times \frac{P_{\text {nano }}}{K_{G}^{\text {micro }}+\sum_{I}\left(\Psi_{I}^{\text {micro }} \times I\right)}, \\
G_{\text {meso } \rightarrow} \text { nano } & =u_{\text {max }}^{\text {meso } \rightarrow \text { nano }} \\
& \times T_{f, \text { meso }} \times \frac{\Psi_{\text {nano }}^{\text {meso }} P_{\text {nano }}}{K_{\text {meso }}^{G}+\sum_{I} \Psi_{\text {nano }}^{\text {meso }} \times I} \times Z_{\text {meso }} .
\end{aligned}
$$

\section{A3 REcoM2}

Particle formation $=G_{\text {nano }}^{\mathrm{POC}}+G_{\text {diat }}^{\mathrm{POC}}+A_{\text {nano }}+A_{\text {diat }}+M_{\text {zoo }}$.

Plankton aggregation and mortality equations:

$$
\begin{aligned}
A_{\text {nano }}= & \left(p_{\text {nano }} \times P_{\text {nano }}+p_{\text {diat }} \times P_{\text {diat }}+p_{\text {det }} \times \text { Detritus }\right) \\
& \times P_{\text {nano }}, \\
A_{\text {nano }}= & \left(p_{\text {nano }} \times P_{\text {nano }}+p_{\text {diat }} \times P_{\text {diat }}+p_{\text {det }} \times \text { Detritus }\right) \\
& \times P_{\text {diat }}, \\
M_{\text {zoo }}= & p_{\text {zoo }} \times Z^{2} .
\end{aligned}
$$

Grazing equations:

$$
\begin{aligned}
G_{\text {nano }}^{\mathrm{POC}}= & f_{\text {graz }}^{\rightarrow \mathrm{POC}} \times G_{\text {nano }}, \\
G_{\text {nano }}= & u_{\max } \times T_{f} \times \frac{\left(P_{\text {nano }}+\Psi_{\text {diat }} P_{\text {diat }}\right)}{K_{\text {zoo }}+\left(P_{\text {nano }}+\Psi_{\text {diat }} P_{\text {diat }}\right)^{2}} \\
& \times P_{\text {nano }} \times Z, \\
G_{\text {diat }}= & u_{\text {max }} \times T_{f} \times \frac{\left(P_{\text {nano }}+\Psi_{\text {diat }} P_{\text {diat }}\right)}{K_{\text {zoo }}+\left(P_{\text {nano }}+\Psi_{\text {diat }} P_{\text {diat }}\right)^{2}} \\
& \times \Psi_{\text {diat }} P_{\text {diat }} \times Z .
\end{aligned}
$$

\section{A4 TOPAZ}

Temperature function:

$T_{f}=e^{k_{\text {Eppley }} \times T}$ 
Grazing:

$$
\begin{aligned}
G_{\text {nano }}= & \min \left(k_{\text {graz }_{\max }}, u_{\max } \times T_{f} \times \frac{P_{\text {nano }}}{P^{\star}}\right) \\
\times & \frac{P_{\text {nano }}^{2}}{P_{\text {nano }}+P_{\min }}, \\
G_{\text {large }}= & \min \left(k_{\text {graz }_{\text {max }}}, u_{\max } \times T_{f} \times\left\{N_{\text {large }}^{\text {graz }}\right\}\right) \times P_{\text {large }}, \\
\left\{N_{\text {large }}^{\text {graz }}\right\} & =\left[\frac{P_{\text {large }}+P_{\text {diaz }}}{P^{\star}}\right]^{\frac{1}{3}} \times \frac{P_{\text {large }}+P_{\text {diaz }}}{P_{\text {large }}+P_{\text {diaz }}+P_{\text {min }}} \\
& \times\left(P_{\text {large }}^{2}+P_{\text {diaz }}^{2}\right)^{\frac{1}{2}}
\end{aligned}
$$

Particle formation:

$$
\begin{aligned}
G_{\text {nano }}^{\mathrm{PON}} & =f_{\text {graz }}^{\text {nano, PON }} \times\left(1.0-f^{\mathrm{sDON}}-f^{\mathrm{lDON}}\right) \\
& \times T_{f} \times G_{\text {nano }}, \\
G_{\text {large }}^{\mathrm{PON}}= & f_{\text {graz }}^{\text {large, PON }} \times\left(1.0-f^{\mathrm{sDON}}-f^{\mathrm{lDON}}\right) \\
& \times T_{f} \times G_{\text {large }} .
\end{aligned}
$$


Table A1. Parameter particle formation BEC.

\begin{tabular}{|c|c|c|c|}
\hline Parameter & Value & Unit & Definition \\
\hline$m_{\text {nano }}$ & 0.1 & $\mathrm{~d}^{-1}$ & nano-linear mortality rate \\
\hline$m_{\text {diat }}$ & 0.1 & $d^{-1}$ & diatom linear mortality rate \\
\hline$p_{\text {nano }}$ & 0.009 & $(\mathrm{mmol} \mathrm{C})^{-1} \mathrm{~m}^{3} \mathrm{~d}^{-1}$ & nano-quadratic mortality rate \\
\hline$p_{\text {diat }}$ & 0.009 & $(\mathrm{mmol} \mathrm{C})^{-1} \mathrm{~m}^{3} \mathrm{~d}^{-1}$ & diatom quadratic mortality rate \\
\hline$e_{\text {nano }}^{\mathrm{POC}}$ & 0.22 & $(\mathrm{mmol} \mathrm{C})^{-1}$ & nano-grazing factor \\
\hline$a_{\text {nano }}^{\max }$ & 0.2 & $\mathrm{~d}^{-1}$ & max. aggregation rate for nanos \\
\hline$a_{\mathrm{diat}}^{\max }$ & 0.2 & $\mathrm{~d}^{-1}$ & max. aggregation rate for diatoms \\
\hline$u_{\max }^{\text {nano }}$ & 2.75 & $d^{-1}$ & max. zoo. growth rate on nanos at $30^{\circ} \mathrm{C}$ \\
\hline$u_{\max }^{\text {diat }}$ & 2.05 & $\mathrm{~d}^{-1}$ & max. zoo. growth rate on diatoms at $30^{\circ} \mathrm{C}$ \\
\hline$u_{\max }^{d i a z}$ & 1.2 & $\mathrm{~d}^{-1}$ & max. zoo. growth rate on diazotrophs at $30^{\circ} \mathrm{C}$ \\
\hline$m_{\mathrm{Z}}$ & 0.1 & $d^{-1}$ & zoo. linear mortality rate \\
\hline$p_{\mathrm{Z}}$ & 0.45 & $(\mathrm{mmol} \mathrm{C})^{-1} \mathrm{~m}^{3} \mathrm{~d}^{-1}$ & zoo. quadratic mortality rate \\
\hline$g$ & 1.05 & $\mathrm{mmol} \mathrm{C} \mathrm{m}^{3}$ & zoo. grazing coefficient \\
\hline$f_{\text {zloss }}^{\text {diat,POC }}$ & 0.1333 & & fraction of zoo. losses routed to POC when eating diatoms \\
\hline$f_{\text {zloss }}^{\text {diaz,POC }}$ & 0.0333 & & fraction of zoo. losses routed to POC when eating diazotrophs \\
\hline$f_{\text {zloss }}^{\text {nano,POC }}$ & 0.06666 & & fraction of zoo. losses routed to POC when eating nanos \\
\hline$f_{\mathrm{graz}}^{\mathrm{CaCO} 3, \mathrm{POC}}$ & 0.4 & & min. proportionality between $Q_{\mathrm{nano}}^{\mathrm{CaCO}_{3}}$ and grazing losses to POC \\
\hline$f_{\text {graz }}^{\text {nano,POC }}$ & 0.24 & & upper limit on fraction of grazing on nanos routed to POC \\
\hline$f_{\text {graz }}^{\text {diat,POC }}$ & 0.26 & & fraction of diatom grazing routed to POC \\
\hline$f_{z}^{\text {diat }}$ & 0.81 & & scaling factor for grazing on diatoms \\
\hline$f_{\text {diat loss }}^{\mathrm{POC}}$ & 0.05 & & fration of diatom loss routed to POC \\
\hline
\end{tabular}


Table A2. Parameter particle formation PISCES.

\begin{tabular}{|c|c|c|c|}
\hline Parameter & Value & Unit & Definition \\
\hline$m_{\text {nano }}$ & 0.01 & $\mathrm{~d}^{-1}$ & nano-linear mortality rate \\
\hline$m_{\text {diat }}$ & 0.01 & $\mathrm{~d}^{-1}$ & diatom linear mortality rate \\
\hline$m_{\text {micro }}$ & 0.03 & $\mathrm{~d}^{-1}$ & micro-linear mortality rate \\
\hline$m_{\text {meso }}$ & 0.005 & $\mathrm{~d}^{-1}$ & meso-linear mortality rate \\
\hline$p_{\text {meso }}$ & 0.03 & $\mathrm{~d}^{-1}$ & meso other mortality rate \\
\hline$p_{\text {nano }}$ & 0.001 & $\mathrm{~L} \mathrm{molC}^{-1} \mathrm{~d}^{-1}$ & nano-quadratic mortality rate \\
\hline$p_{\text {diat }}$ & $0.001+0.02 \times\left(1.0-N_{\mathrm{lim}}^{\mathrm{diat}}\right)$ & $\mathrm{L} \mathrm{molC}^{-1} \mathrm{~d}^{-1}$ & diatom quadratic mortality rate \\
\hline$K_{\mathrm{M}}$ & $0.01 \mathrm{e}^{-6}$ & $\mathrm{molC} \mathrm{L}^{-1}$ & half-saturation constant for mortality \\
\hline$K_{\mathrm{G}}$ & $20 \mathrm{e}^{-6}$ & $\mathrm{molC} \mathrm{L}^{-1}$ & half-saturation constant for grazing \\
\hline$u_{\max }^{\operatorname{micro} \rightarrow \text { nano }}$ & 4.0 & $\mathrm{~d}^{-1}$ & max. micro zoo. growth rate on nanos $\left(\right.$ at $\left.0^{\circ} \mathrm{C}\right)$ \\
\hline$u_{\max }^{\operatorname{micro}} \rightarrow$ diat & 4.0 & $\mathrm{~d}^{-1}$ & max. micro zoo. growth rate on diatoms (at $0^{\circ} \mathrm{C}$ ) \\
\hline$u_{\max }^{\operatorname{meso}} \rightarrow$ nano & 0.7 & $d^{-1}$ & max. meso zoo. growth rate on nanos at $0^{\circ} \mathrm{C}$ \\
\hline$u_{\max }^{\operatorname{meso}} \rightarrow$ diat & 0.7 & $d^{-1}$ & max. meso zoo. growth rate on diatoms at $0^{\circ} \mathrm{C}$ \\
\hline$u_{\max }^{\operatorname{meso}} \rightarrow$ micro & 0.7 & $\mathrm{~d}^{-1}$ & max. meso zoo. growth rate on micro at $0^{\circ} \mathrm{C}$ \\
\hline$\Psi_{\text {nano }}^{\text {micro }}$ & 0.5 & & preference coefficient for micro-grazing on nanos \\
\hline$\Psi_{\text {diat }}^{\text {micro }}$ & 0.5 & & preference coefficient for micro-grazing on diatoms \\
\hline$\Psi_{\text {nano }}^{\text {meso }}$ & 0.2 & & preference coefficient for meso-grazing on nanos \\
\hline$\Psi_{\text {diat }}^{\text {meso }}$ & 1.0 & & preference coefficient for meso-grazing on diatoms \\
\hline$\Psi_{\text {micro }}^{\text {meso }}$ & 1.0 & & preference coefficient for meso-grazing on micro \\
\hline$f_{\text {mort }}^{\text {nano,POCs }}$ & $1-0.5 R_{\mathrm{CaCO}_{3}}$ & & fraction of nano-mortality routed to POCs \\
\hline$f_{\text {mort }}^{\text {nano,POCl }}$ & $0.5 \mathrm{R}_{\mathrm{CaCO}_{3}}$ & & fraction of nano-mortality routed to $\mathrm{POCl}$ \\
\hline$f_{\text {mort }}^{\text {diat,POCs }}$ & 0.5 & & fraction of diatom mortality routed to POCs \\
\hline$f_{\text {mort }}^{\text {diat,POCl }}$ & 0.5 & & fraction of diatom mortality routed to $\mathrm{POCl}$ \\
\hline$f_{\text {agg }}^{\text {nano,POCs }}$ & $1-0.5 R_{\mathrm{CaCO}_{3}}$ & & fraction of nano-aggregation routed to POCs \\
\hline$f_{\text {agg }}^{\text {nano,POCl }}$ & $0.5 R_{\mathrm{CaCO}_{3}}$ & & fraction of nano-aggregation routed to $\mathrm{POCl}$ \\
\hline$f_{\text {agg }}^{\text {diat,POCs }}$ & 0 & & fraction of diatom aggregation routed to POCs \\
\hline$f_{\text {agg }}^{\text {diat, }} \mathrm{POCl}$ & 1 & & fraction of diatom aggregation routed to $\mathrm{POCl}$ \\
\hline$f_{\mathrm{graz}}^{\rightarrow} \mathrm{POC}$ & 0.3 & & fraction of grazed material routed to POC (all PFTs) \\
\hline$R_{\mathrm{CaCO}_{3}}$ & & & fraction of calcifying organisms of nanos \\
\hline$N_{\text {lim }}^{\text {diat }}$ & & & diatom nutrient limitation \\
\hline
\end{tabular}


Table A3. Parameter particle formation REcoM2.

\begin{tabular}{lrll}
\hline Parameter & Value & Unit & Definition \\
\hline$p_{\text {det }}$ & 0.0165 & $\mathrm{~m}^{3} \mathrm{mmolN}^{-1} \mathrm{~d}^{-1}$ & detritus specific aggregation rate \\
$p_{\text {nano }}$ & 0.015 & $\mathrm{~m}^{3} \mathrm{mmolN}^{-1} \mathrm{~d}^{-1}$ & nano-quadratic mortality rate/specific aggregation rate \\
$p_{\text {diat }}$ & 0.015 & $\mathrm{~m}^{3} \mathrm{mmolN}^{-1} \mathrm{~d}^{-1}$ & diatom quadratic mortality rate \\
$p_{\text {zoo }}$ & 0.05 & $\mathrm{~m}^{3} \mathrm{mmolN}^{-1} \mathrm{~d}^{-1}$ & zooplankton quadratic mortality rate \\
$K_{\text {Zoo }}$ & 0.35 & $\left(\mathrm{mmolN} \mathrm{m}^{-3}\right)^{2}$ & half-saturation constant for grazing \\
$u_{\text {max }}$ & 2.4 & $\mathrm{~d}^{-1}$ & max. zooplankton growth rate \\
$\Psi_{\text {diat }}$ & 0.5 & & preference coefficient for grazing on diatoms \\
$f_{\text {graz }}^{\rightarrow \text { POC }}$ & 0.4 & & fraction of grazing routed to POC/grazing efficiency \\
\hline
\end{tabular}

Table A4. TOPAZ parameters.

\begin{tabular}{lrll}
\hline Parameter & Value & Unit & Description \\
\hline $\mathrm{K}_{\text {Eppley }}$ & 0.063 & ${ }^{\circ} \mathrm{C}^{-1}$ & temperature dependence factor \\
$u_{\max }$ & $0.19 / 86400$ & $\mathrm{~s}^{-1}$ & grazing rate at $0^{\circ} \mathrm{C}$ \\
$P^{\star}$ & $1.9 \mathrm{e}^{-6} \times \frac{16}{106}$ & $\mathrm{molN} \mathrm{kg}^{-1}$ & pivot phyto concentration for grazing allometry \\
$P_{\text {min }}$ & $1 \mathrm{e}^{-10}$ & $\mathrm{molN} \mathrm{kg}^{-1}$ & min phyto concentration threshold for grazing \\
$f_{\text {graz }}^{\text {nano, PON }}$ & 0.18 & & fraction of nano-grazing to detritus at $0^{\circ} \mathrm{C}$ \\
$f_{\text {graz }}^{\text {garg }}$ & 0.93 & & fraction of large grazing to detritus at $0^{\circ} \mathrm{C}$ \\
$f^{\text {sDON }}$ & 0.025 & & fraction of non-detritus grazing going to sDON \\
$f^{\text {lDON }}$ & 0.06 & & fraction of non-detritus grazing going to lDON \\
\hline
\end{tabular}


Acknowledgements. The research leading to these results has received funding from the European Community's Seventh Framework Programme (FP7 2007-2013) under grant agreement no. 238366. Meike Vogt and Nicolas Gruber acknowledge funding by ETH Zürich. Judith Hauck was funded by the Helmholtz PostDoc Programme (Initiative and Networking Fund of the Helmholtz Association). Scott C. Doney and Ivan D. Lima acknowledge the support of the National Science Foundation through the Center for Microbial Oceanography Research and Education (C-MORE), an NSF Science and Technology Center (EF-0424599). We thank the climate modelling groups for calculating and providing their model output. We also acknowledge the Marine Ecosystem Model Intercomparison Project, and the World Climate Research Programme's Working Group on Coupled Modelling, which is responsible for CMIP. For CMIP the US Department of Energy's Program for Climate Model Diagnosis and Intercomparison provided coordinating support and led the development of software infrastructure in partnership with the Global Organization for Earth System Science Portals.

Edited by: L. Cotrim da Cunha

\section{References}

Alldredge, A. L. and Jackson, G. A.: Aggregation in Marine Systems, Deep-Sea Res. Pt. II, 42, 1-7, 1995.

Allen, J. I., Aiken, J., Anderson, T. R., Buitenhuis, E., Cornell, S., Geider, R. J., Haines, K., Hirata, T., Holt, J., and Le Quéré, C.: Marine ecosystem models for earth systems applications: The MarQUEST experience, J. Marine Syst., 81, 19-33, doi:10.1016/j.jmarsys.2009.12.017, 2010.

Armstrong, R., Lee, C., Hedges, J., Honjo, S., and Wakeham, S.: A new, mechanistic model for organic carbon fluxes in the ocean based on the quantitative association of POC with ballast minerals, Deep-Sea Res. Pt. II, 49, 219-236, doi:10.1016/S09670645(01)00101-1, 2002.

Aumont, O. and Bopp, L.: Globalizing results from ocean in situ iron fertilization studies, Global Biogeochem. Cy., 20, 1-15, doi:10.1029/2005GB002591, 2006.

Behrenfeld, M. J. and Falkowski, P. G.: Photosynthetic rates derived from satellite-based chlorophyll concentration, Limnol. Oceanogr., 42, 1-20, 1997.

Besiktepe, S. and Dam, H.: Coupling of ingestion and defecation as a function of diet in the calanoid copepod Acartia tonsa, Mar. Ecol.-Prog. Ser., 229, 151-164, doi:10.3354/meps229151, 2002.

Bopp, L., Monfray, P., Aumont, O., Dufresne, J., Le Treut, H., Madec, G., Terray, L., and Orr, J.: Potential impact of climate change on marine export production, Global Biogeochem. Cy., 15, 81-100, 2001.

Bopp, L., Aumont, O., Cadule, P., Alvain, S., and Gehlen, M.: Response of diatoms distribution to global warming and potential implications: A global model study, Geophys. Res. Lett., 32, $2-$ 5, doi:10.1029/2005GL023653, 2005.

Bopp, L., Resplandy, L., Orr, J. C., Doney, S. C., Dunne, J. P., Gehlen, M., Halloran, P., Heinze, C., Ilyina, T., Séférian, R., Tjiputra, J., and Vichi, M.: Multiple stressors of ocean ecosystems in the 21st century: projections with CMIP5 models,
Biogeosciences, 10, 6225-6245, doi:10.5194/bg-10-6225-2013, 2013.

Bowie, A. R., Trull, T. W., and Dehairs, F.: Estimating the sensitivity of the subantarctic zone to environmental change: The SAZSense project, Deep-Sea Res. Pt. II, 58, 2051-2058, 2011.

Burd, A. B. and Jackson, G. A.: Particle Aggregation, Annual Review of Marine Science, 1, 65-90, doi:10.1146/annurev.marine.010908.163904, 2009.

Cabré, A., Marinov, I., and Leung, S.: Consistent global responses of marine ecosystems to future climate change across the IPCC AR5 earth system models, Clim. Dynam., doi:10.1007/s00382014-2374-3, 2014.

Calbet, A.: Mesozooplankton grazing effect on primary production : A global comparative analysis in marine ecosystems, Limnol. Oceanogr., 46, 1824-1830, 2001.

Calbet, A. and Landry, M. R.: Phytoplankton growth, microzooplankton grazing, and carbon cycling in marine systems, Limnol. Oceanogr., 49, 51-57, 2004.

Carr, M., Friedrichs, M., Schmeltz, M., Noguchiaita, M., Antoine, D., Arrigo, K., Asanuma, I., Aumont, O., Barber, R., and Behrenfeld, M.: A comparison of global estimates of marine primary production from ocean color, Deep-Sea Res. Pt. II, 53, 741-770, doi:10.1016/j.dsr2.2006.01.028, 2006.

Dunne, J. P., Sarmiento, J. L., and Gnanadesikan, A.: A synthesis of global particle export from the surface ocean and cycling through the ocean interior and on the seafloor, Global Biogeochem. Cy., 21, 1-16, doi:10.1029/2006GB002907, 2007.

Dunne, J. P., Hales, B., and Toggweiler, J. R.: Global calcite cycling constrained by sediment preservation controls, Global Biogeochem. Cy., 26, GB3023, doi:10.1029/2010GB003935, 2012.

Dunne, J. P., John, J. G., Shevliakova, E., Stouffer, R. J., Krasting, J. P., Malyshev, S. L., Milly, P. C. D., Sentman, L. T., Adcroft, A. J., Cooke, W., Dunne, K. A., Griffies, S. M., Hallberg, R. W., Harrison, M. J., Levy, H., Wittenberg, A. T., Phillips, P. J., and Zadeh, N.: GFDL's ESM2 Global Coupled Climate-Carbon Earth System Models. Part II: Carbon System Formulation and Baseline Simulation Characteristics, J. Climate, 26, 2247-2267, doi:10.1175/JCLI-D-12-00150.1, 2013.

Dutkiewicz, S., Scott, J. R., and Follows, M. J.: Winners and losers: Ecological and biogeochemical changes in a warming ocean, Global Biogeochem. Cy., 27, 463-477, doi:10.1002/gbc.20042, 2013.

Ebersbach, F. and Trull, T.: Sinking particle properties from polyacrylamide gels during the KErguelen Ocean and Plateau compared Study (KEOPS): Zooplankton control of carbon export in an area of persistent natural iron inputs in the Southern Ocean, Limnol. Oceanogr., 53, 212-224, 2008.

Ebersbach, F., Trull, T. W., Davies, D. M., and Bray, S. G.: Controls on mesopelagic particle fluxes in the Sub-Antarctic and Polar Frontal Zones in the Southern Ocean south of Australia in summer - Perspectives from free-drifting sediment traps, DeepSea Res. Pt. II, 58, 2260-2276, doi:10.1016/j.dsr2.2011.05.025, 2011.

Falkowski, P. G., Laws, E. A., Barber, R. T., and Murray, J. W.: Phytoplankton and their role in primary, new, and export production, in: Ocean Biogeochemistry: The Role of the Ocean Carbon Cycle in Global Change, edited by: Fasham, M. J. R., The IGBP Series, chap. 4, Springer, Berlin, 99-121, 2003. 
Fu, W., Randerson, J., and Moore, J. K.: Climate change impacts on net primary production (NPP) and export production (EP) regulated by increasing stratification and phytoplankton community structure in CMIP5 models, Biogeosciences Discuss., 12, 12851-12897, doi:10.5194/bgd-12-12851-2015, 2015.

Guidi, L., Chaffron, S., Bittner, L., Eveillard, D., Larhlimi, A., Roux, S., Darzi, Y., Audic, S., Berline, L., Brum, J., Coelho, L. P., Espinoza, J. C. I., Malviya, S., Sunagawa, S., Dimier, C., Kandels-Lewis, S., Picheral, M., Poulain, J., Searson, S., Coordinators, T. O., Stemmann, L., Not, F., Hingamp, P., Speich, S., Follows, M., Karp-Boss, L., Boss, E., Ogata, H., Pesant, S., Weissenbach, J., Wincker, P., Acinas, S. G., Bork, P., de Vargas, C., Iudicone, D., Sullivan, M. B., Raes, J., Karsenti, E., Bowler, C., and Gorsky, G.: Plankton networks driving carbon export in the oligotrophic ocean, Nature, 532, 465-470, doi:10.1038/nature16942, 2016

Hansell, D. A. and Carlson, C. A.: Biogeochemistry of marine dissolved organic matter, Academic Press, 2002.

Hashioka, T., Vogt, M., Yamanaka, Y., Le Quéré, C., Buitenhuis, E. T., Aita, M. N., Alvain, S., Bopp, L., Hirata, T., Lima, I., Sailley, S., and Doney, S. C.: Phytoplankton competition during the spring bloom in four plankton functional type models, Biogeosciences, 10, 6833-6850, doi:10.5194/bg-10-6833-2013, 2013.

Hauck, J., Völker, C., Wang, T., Hoppema, M., Losch, M., and Wolf-Gladrow, D. A.: Seasonally different carbon flux changes in the Southern Ocean in response to the southern annular mode, Global Biogeochem. Cy., 27, 1236-1245, doi:10.1002/2013GB004600, 2013.

Hauck, J., Völker, C., Wolf-Gladrow, D., Laufkötter, C., Vogt, M., Aumont, O., Bopp, L., Buitenhuis, E., Doney, S. C., Dunne, J., Gruber, N., Hashioka, T., John, J., Le Quéré, C., Lima, I. D., Nakano, H., Seferian, R., and Totterdell, I.: On the Southern Ocean $\mathrm{CO}_{2}$ uptake and the role of the biological carbon pump in the 21st century, Global Biogeochem. Cy., 29, 1451-1470, doi:10.1002/2015GB005140, 2015.

Henson, S. A., Sanders, R., Madsen, E., Morris, P. J., Le Moigne, F., and Quartly, G. D.: A reduced estimate of the strength of the ocean's biological carbon pump, Geophys. Res. Lett., 38, L04606, doi:10.1029/2011GL046735, 2011.

Henson, S. A., Sanders, R., and Madsen, E.: Global patterns in efficiency of particulate organic carbon export and transfer to the deep ocean, Global Biogeochem. Cy., 26, GB1028, doi:10.1029/2011GB004099, 2012.

Hurrell, J. W., Holland, M. M., Gent, P. R., Ghan, S., Kay, J. E., Kushner, P. J., Lamarque, J.-F., Large, W. G., Lawrence, D., Lindsay, K., Lipscomb, W. H., Long, M. C., Mahowald, N., Marsh, D. R., Neale, R. B., Rasch, P., Vavrus, S., Vertenstein, M., Bader, D., Collins, W. D., Hack, J. J., Kiehl, J., and Marshall, S.: The Community Earth System Model: A Framework for Collaborative Research, B. Am. Meteorol. Soc., 94, 13391360, doi:10.1175/BAMS-D-12-00121.1, 2013.

Iversen, M. H. and Robert, M. L.: Ballasting effects of smectite on aggregate formation and export from a natural plankton community, Mar. Chem., 175, 18-27, doi:10.1016/j.marchem.2015.04.009, 2015.

Jin, X., Gruber, N., Dunne, J. P., Sarmiento, J. L., and Armstrong, R. A.: Diagnosing the contribution of phytoplankton functional groups to the production and export of particulate organic carbon, $\mathrm{CaCO}_{3}$, and opal from global nutrient and alkalinity distributions, Global Biogeochem. Cy., 20, 1-17, doi:10.1029/2005GB002532, 2006.

Kawamiya, M., Kishi, M. J., and Suginohara, N.: An ecosystem model for the North Pacific embedded in a general circulation model Part I : Model description and characteristics of spatial distributions of biological variables, J. Marine Syst., 25, 129$157,2000$.

Kim, J.-M., Lee, K., Shin, K., Yang, E. J., Engel, A., Karl, D. M., and Kim, H.-C.: Shifts in biogenic carbon flow from particulate to dissolved forms under high carbon dioxide and warm ocean conditions, Geophys. Res. Lett., 38, 1-5, doi:10.1029/2011GL047346, 2011.

Klaas, C. and Archer, D. E.: Association of sinking organic matter with various types of mineral ballast in the deep sea: Implications for the rain ratio, Global Biogeochem. Cy., 16, 1116, doi:10.1029/2001GB001765, 2002.

Kriest, I. and Oschlies, A.: On the treatment of particulate organic matter sinking in large-scale models of marine biogeochemical cycles, Biogeosciences, 5, 55-72, doi:10.5194/bg-5-55-2008, 2008.

Kvale, K. F., Meissner, K. J., and Keller, D. P.: Potential increasing dominance of heterotrophy in the global ocean, Environ. Res. Lett., 10, 074009, doi:10.1088/1748-9326/10/7/074009, 2015.

Laufkötter, C., Vogt, M., Gruber, N., Aita-Noguchi, M., Aumont, O., Bopp, L., Buitenhuis, E., Doney, S. C., Dunne, J., Hashioka, T., Hauck, J., Hirata, T., John, J., Le Quéré, C., Lima, I. D., Nakano, H., Seferian, R., Totterdell, I., Vichi, M., and Völker, C.: Drivers and uncertainties of future global marine primary production in marine ecosystem models, Biogeosciences, 12, 69556984, doi:10.5194/bg-12-6955-2015, 2015.

Laurenceau-Cornec, E. C., Trull, T. W., Davies, D. M., Bray, S. G., Doran, J., Planchon, F., Carlotti, F., Jouandet, M.-P., Cavagna, A.-J., Waite, A. M., and Blain, S.: The relative importance of phytoplankton aggregates and zooplankton fecal pellets to carbon export: insights from free-drifting sediment trap deployments in naturally iron-fertilised waters near the Kerguelen Plateau, Biogeosciences, 12, 1007-1027, doi:10.5194/bg-121007-2015, 2015.

Laws, E. A., Falkowski, P. G., Smith Jr, W. O., Ducklow, H., and McCarthy, J. J.: Temperature effects on export production in the open ocean, Global Biogeochem. Cy., 14, 1231-1246, 2000.

Leung, S., Cabré, A., and Marinov, I.: A latitudinally banded phytoplankton response to 21 st century climate change in the Southern Ocean across the CMIP5 model suite, Biogeosciences, 12, 57155734, doi:10.5194/bg-12-5715-2015, 2015.

Lima, I. D., Lam, P. J., and Doney, S. C.: Dynamics of particulate organic carbon flux in a global ocean model, Biogeosciences, 11, 1177-1198, doi:10.5194/bg-11-1177-2014, 2014.

Lindsay, K., Bonan, G. B., Doney, S. C., Hoffman, F. M., Lawrence, D. M., Long, M. C., Mahowald, N. M., Moore, J. K., Randerson, J. T., and Thornton, P. E.: Preindustrial Control and 20th Century Carbon Cycle Experiments with the Earth System Model CESM1(BGC), J. Climate, 1, 8981-9005, doi:10.1175/JCLI-D12-00565.1, 2014.

Lomas, M. W. and Moran, S. B.: Evidence for aggregation and export of cyanobacteria and nano-eukaryotes from the Sargasso Sea euphotic zone, Biogeosciences, 8, 203-216, doi:10.5194/bg-8203-2011, 2011. 
López-Urrutia, A., San Martin, E., Harris, R. P., and Irigoien, X.: Scaling the metabolic balance of the oceans., P. Natl. Acad. Sci. USA, 103, 8739-44, doi:10.1073/pnas.0601137103, 2006.

Marinov, I., Doney, S. C., and Lima, I. D.: Response of ocean phytoplankton community structure to climate change over the $21 \mathrm{st}$ century: partitioning the effects of nutrients, temperature and light, Biogeosciences, 7, 3941-3959, doi:10.5194/bg-7-39412010, 2010.

Marinov, I., Doney, S. C., Lima, I. D., Lindsay, K., Moore, J. K., and Mahowald, N.: North-South asymmetry in the modeled phytoplankton community response to climate change over the 21st century, Global Biogeochem. Cy., 27, 1274-1290, doi:10.1002/2013GB004599, 2013.

Marsay, C. M., Sanders, R. J., Henson, S. A., Pabortsava, K., Achterberg, E. P., and Lampitt, R. S.: Attenuation of sinking particulate organic carbon flux through the mesopelagic ocean, P. Natl. Acad. Sci. USA, 112, 1089-1094, doi:10.1073/pnas.1415311112, 2015.

Moore, J., Doney, S., Kleypas, J., Glover, D., and Fung, I.: An intermediate complexity marine ecosystem model for the global domain, Deep-Sea Res. Pt. II, 49, 403-462, doi:10.1016/S09670645(01)00108-4, 2002.

Moore, J. K., Doney, S. C., and Lindsay, K.: Upper ocean ecosystem dynamics and iron cycling in a global threedimensional model, Global Biogeochem. Cy., 18, 1-21, doi:10.1029/2004GB002220, 2004.

Moore, J. K., Lindsay, K., Doney, S. C., Long, M. C., and Misumi, K.: Marine Ecosystem Dynamics and Biogeochemical Cycling in the Community Earth System Model [CESM1(BGC)]: Comparison of the 1990s with the 2090s under the RCP4.5 and RCP8.5 Scenarios, J. Climate, 26, 9291-9312, doi:10.1175/JCLI-D-1200566.1, 2013.

Najjar, R. G., Jin, X., Louanchi, F., Aumont, O., Caldeira, K., Doney, S. C., Dutay, J.-C., Follows, M., Gruber, N., Joos, F., Lindsay, K., Maier-Reimer, E., Matear, R. J., Matsumoto, K., Monfray, P., Mouchet, A., Orr, J. C., Plattner, G.-K., Sarmiento, J. L., Schlitzer, R., Slater, R. D., Weirig, M.-F., Yamanaka, Y., and Yool, A.: Impact of circulation on export production, dissolved organic matter, and dissolved oxygen in the ocean: Results from Phase II of the Ocean Carbon-cycle Model Intercomparison Project (OCMIP-2), Global Biogeochem. Cy., 21, GB3007, doi:10.1029/2006GB002857, 2007.

Omand, M. M. and Mahadevan, A.: The shape of the oceanic nitracline, Biogeosciences, 12, 3273-3287, doi:10.5194/bg-12-32732015, 2015.

Quéguiner, B.: Iron fertilization and the structure of planktonic communities in high nutrient regions of the Southern Ocean, Deep-Sea Res. Pt. II, 90, 43-54, doi:10.1016/j.dsr2.2012.07.024, 2013.

Richardson, T. L. and Jackson, G. a.: Small phytoplankton and carbon export from the surface ocean, 315, 838-840, doi:10.1126/science.1133471, 2007.

Sailley, S., Vogt, M., Doney, S., Aita, M., Bopp, L., Buitenhuis, E., Hashioka, T., Lima, I., Le Quéré, C., and Yamanaka, Y.: Comparing food web structures and dynamics across a suite of global marine ecosystem models, Ecol. Model., 261-262, 43-57, doi:10.1016/j.ecolmodel.2013.04.006, 2013.

Sarmiento, J. L. and Gruber, N.: Ocean Biogeochemical Dynamis, Princeton University Press, Princeton, 2006.
Schlitzer, R.: Export production in the equatorial and North Pacific derived from dissolved oxygen, nutrient and carbon data, J. Oceanogr., 60, 53-62, doi:10.1023/B:JOCE.0000038318.38916.e6, 2004.

Schmittner, A., Oschlies, A., Matthews, H. D., and Galbraith, E. D.: Future changes in climate, ocean circulation, ecosystems, and biogeochemical cycling simulated for a business-as-usual $\mathrm{CO}_{2}$ emission scenario until year $4000 \mathrm{AD}$, Global Biogeochem. Cy., 22, GB1013, doi:10.1029/2007GB002953, 2008.

Siegel, D. A., Buesseler, K. O., Doney, S. C., Sailley, S. F., Behrenfeld, M. J., and Boyd, P. W.: Global assessment of ocean carbon export by combining satellite observations and food-web models, Global Biogeochem. Cy., 28, 181-196, doi:10.1002/2013GB004743, 2014.

Smetacek, V., Klaas, C., Strass, V. H., Assmy, P., Montresor, M., Cisewski, B., Savoye, N., Webb, A., D’Ovidio, F., Arrieta, J. M., Bathmann, U., Bellerby, R., Berg, G. M., Croot, P., Gonzalez, S., Henjes, J., Herndl, G. J., Hoffmann, L. J., Leach, H., Losch, M., Mills, M. M., Neill, C., Peeken, I., Röttgers, R., Sachs, O., Sauter, E., Schmidt, M. M., Schwarz, J., Terbrüggen, A., and Wolf-Gladrow, D.: Deep carbon export from a Southern Ocean iron-fertilized diatom bloom., Nature, 487, 313-319, doi:10.1038/nature11229, 2012.

Steinacher, M., Joos, F., Frölicher, T. L., Bopp, L., Cadule, P., Cocco, V., Doney, S. C., Gehlen, M., Lindsay, K., Moore, J. K., Schneider, B., and Segschneider, J.: Projected 21st century decrease in marine productivity: a multi-model analysis, Biogeosciences, 7, 979-1005, doi:10.5194/bg-7-979-2010, 2010.

Stoecker, D. K.: Particle production by planktonic ciliates, Limnol. Oceanogr., 29, 930-940, doi:10.4319/lo.1984.29.5.0930, 1984.

Taucher, J. and Oschlies, A.: Can we predict the direction of marine primary production change under global warming?, Geophys. Res. Lett., 38, 1-6, doi:10.1029/2010GL045934, 2011.

Taylor, K. E., Stouffer, R. J., and Meehl, G. A.: An Overview of CMIP5 and the Experiment Design, B. Am. Meteorol. Soc., 93, 485-498, doi:10.1175/BAMS-D-11-00094.1, 2012.

van Vuuren, D. P., Edmonds, J., Kainuma, M., Riahi, K., Thomson, A., Hibbard, K., Hurtt, G. C., Kram, T., Krey, V., Lamarque, J.F., Masui, T., Meinshausen, M., Nakicenovic, N., Smith, S. J., and Rose, S. K.: The representative concentration pathways: an overview, Climatic Change, 109, 5-31, doi:10.1007/s10584-0110148-z, 2011.

Vogt, M., Hashioka, T., Payne, M. R., Buitenhuis, E. T., Quéré, C. L., Alvain, S., Aita, M. N., Bopp, L., Doney, S. C., Hirata, T., Lima, I., Sailley, S., and Yamanaka, Y.: The distribution, dominance patterns and ecological niches of plankton functional types in Dynamic Green Ocean Models and satellite estimates, Biogeosciences Discuss., 10, 17193-17247, doi:10.5194/bgd10-17193-2013, 2013.

Voldoire, A., Sanchez-Gomez, E., Salas y Mélia, D., Decharme, B., Cassou, C., Sénési, S., Valcke, S., Beau, I., Alias, A., Chevallier, M., Déqué, M., Deshayes, J., Douville, H., Fernandez, E., Madec, G., Maisonnave, E., Moine, M.-P., Planton, S., SaintMartin, D., Szopa, S., Tyteca, S., Alkama, R., Belamari, S., Braun, A., Coquart, L., and Chauvin, F.: The CNRM-CM5.1 global climate model: description and basic evaluation, Clim. Dynam., 40, 2091-2121, doi:10.1007/s00382-011-1259-y, 2012.

Watanabe, S., Hajima, T., Sudo, K., Nagashima, T., Takemura, T., Okajima, H., Nozawa, T., Kawase, H., Abe, M., Yokohata, T., 
Ise, T., Sato, H., Kato, E., Takata, K., Emori, S., and Kawamiya, M.: MIROC-ESM 2010: model description and basic results of CMIP5-20c3m experiments, Geosci. Model Dev., 4, 845-872, doi:10.5194/gmd-4-845-2011, 2011.

Westberry, T., Behrenfeld, M. J., Siegel, D. A., and Boss, E.: Carbon-based primary productivity modeling with vertically resolved photoacclimation, Global Biogeochem. Cy., 22, GB2024, doi:10.1029/2007GB003078, 2008.
Wilson, J. D., Barker, S., and Ridgwell, A.: Assessment of the spatial variability in particulate organic matter and mineral sinking fluxes in the ocean interior: Implications for the ballast hypothesis, Global Biogeochem. Cy., 26, GB4011, doi:10.1029/2012GB004398, 2012. 